Published in final edited form as:

Nat Immunol. 2016 December ; 17(12): 1352-1360. doi:10.1038/ni.3575.

\title{
RASGRP1 deficiency causes immunodeficiency with impaired cytoskeletal dynamics
}

\author{
Elisabeth Salzer ${ }^{1,2}$, Deniz Cagdas ${ }^{\# 3}$, Miroslav Hons ${ }^{\# 4}$, Emily M Mace ${ }^{\# 5}$, Wojciech \\ Garncarz $^{1,2}$, Özlem Yüce Petronczki ${ }^{1,2}$, René Platzer ${ }^{6}$, Laurène Pfajfer ${ }^{1,2}$, Ivan Bilic ${ }^{1}$, Sol A \\ Ban $^{1}$, Katharina L Willmann ${ }^{1}$, Malini Mukherjee ${ }^{5}$, Verena Supper ${ }^{6}$, Hsiang Ting Hsu ${ }^{5}$, Pinaki \\ P Banerjee $^{5}$, Papiya Sinha ${ }^{5}$, Fabienne McClanahan ${ }^{7}$, Gerhard J Zlabinger ${ }^{8}$, Winfried F \\ Pickl $^{9}$, John G Gribben ${ }^{7}$, Hannes Stockinger ${ }^{6}$, Keiryn L Bennett ${ }^{1}$, Johannes B Huppa ${ }^{6}$, Loïc \\ Dupré $^{1,2,10}$, Özden Sanal ${ }^{3}$, Ulrich Jäger ${ }^{11}$, Michael Sixt ${ }^{\# 4}$, Ilhan Tezcan ${ }^{\# 3}$, Jordan S \\ Orange ${ }^{\# 5}$, and Kaan Boztug 1,2,12,13 \\ ${ }^{1}$ CeMM Research Center for Molecular Medicine of the Austrian Academy of Sciences, Vienna, \\ Austria \\ ${ }^{2}$ Ludwig Boltzmann Institute for Rare and Undiagnosed Diseases, Vienna, Austria \\ ${ }^{3}$ Section of Pediatric Immunology, Hacettepe University, Insan Dogramaci Children's Hospital, \\ Ankara, Turkey \\ ${ }^{4}$ Institute of Science and Technology Austria, Klosterneuburg, Austria \\ ${ }^{5}$ Center for Human Immunobiology, Baylor College of Medicine and Texas Children's Hospital, \\ Houston, Texas, USA \\ ${ }^{6}$ Institute for Hygiene and Applied Immunology, Center for Pathophysiology, Infectiology and \\ Immunology, Medical University of Vienna, Vienna, Austria \\ ${ }^{7}$ Centre for Haemato-Oncology, Barts Cancer Institute - a CR-UK Centre of Excellence, Queen \\ Mary University of London, London, UK \\ ${ }^{8}$ Institute of Immunology, Center of Pathophysiology, Infectiology and Immunology, Medical \\ University of Vienna, Vienna, Austria
}

\footnotetext{
Correspondence should be addressed to K.B. (kaan.boztug@rud.lbg.ac.at). Author Contributions

E.S. performed most of the experiments, analyzed data, interpreted results, and, together with K.B., wrote the initial draft and revised version of the manuscript. D.C., I.T. and Ö.S. cared for the patient, and provided and interpreted clinical and immunological data. M.H. and E.S. performed migration and Lifeact experiments. M.S. provided critical input to the content of the manuscript. E.M.M., P.S., M.M., P.P.B., H.T.H. and J.S.O. performed and interpreted NK-cell immunological synapse experiments and detailed flowcytometry-based NK-cell immunophenotyping. S.A.B. and E.S. identified the RASGRP1 mutation and performed initial experiments. R.P. and J.B.H. performed lipid bilayer calcium-flux experiments, and analyzed and interpreted data. L.P. generated an untransformed $\mathrm{CD} 8^{+} \mathrm{T}$ cell line from the patient and performed the $\mathrm{CD} 8^{+} \mathrm{T}$ cell cytotoxic assays. H.S. and V.S. performed proliferation analyses together with E.S. and provided critical input. Ö.Y.P. and L.D. performed the immunofluorescence experiments to quantify RhoA activation. K.L.W., W.G. and I.B. performed experiments and provided critical input. F.M., J.G.G. and U.J. helped with migration analyses. K.L.B. performed mass spectrometry analyses. W.F.P. and G.J.Z. performed thymidine incorporation assays, chromium release assays and analyses of autoantibody titers. K.B. conceived of and coordinated the study, provided laboratory resources, interpreted data, supervised E.S., W.G., Ö.Y.P., I.B., S.B. and K.W., wrote the manuscript together with E.S. and took overall responsibility for the study. All of the authors provided critical input and agreed to this publication.

Competing Financial Interests

The authors declare no competing financial interests.

Reprints and permissions information is available online at http://www.nature.com/reprints/index.html.
} 
${ }^{9}$ Christian Doppler Laboratory for Immunomodulation and Institute of Immunology, Center for Pathophysiology, Infectiology and Immunology, Medical University of Vienna, Vienna, Austria

${ }^{10}$ Centre de Physiopathologie de Toulouse Purpan (CPTP), INSERM, UMR1043, Toulouse Purpan University Hospital, Toulouse, France

${ }^{11}$ Department of Medicine I, Division of Hematology and Hemostaseology, Medical University of Vienna, Vienna, Austria

${ }^{12}$ Department of Pediatrics and Adolescent Medicine, Medical University of Vienna, Vienna, Austria

${ }^{13}$ St. Anna Kinderspital and Children's Cancer Research Institute, Department of Pediatrics, Medical University of Vienna, Vienna, Austria

\# These authors contributed equally to this work.

\section{Abstract}

RASGRP1 is an important guanine nucleotide exchange factor and activator of the RAS-MAPK pathway following $\mathrm{T}$ cell antigen receptor (TCR) signaling. The consequences of RASGRP1 mutations in humans are unknown. In a patient with recurrent bacterial and viral infections, born to healthy consanguineous parents, we used homozygosity mapping and exome sequencing to identify a biallelic stop-gain variant in $R A S G R P 1$. This variant segregated perfectly with the disease and has not been reported in genetic databases. RASGRP1 deficiency was associated in $\mathrm{T}$ cells and B cells with decreased phosphorylation of the extracellular-signal-regulated serine kinase ERK, which was restored following expression of wild-type RASGRP1. RASGRP1 deficiency also resulted in defective proliferation, activation and motility of T cells and B cells. RASGRP1deficient natural killer (NK) cells exhibited impaired cytotoxicity with defective granule convergence and actin accumulation. Interaction proteomics identified the dynein light chain DYNLL1 as interacting with RASGRP1, which links RASGRP1 to cytoskeletal dynamics. RASGRP1-deficient cells showed decreased activation of the GTPase RhoA. Treatment with lenalidomide increased RhoA activity and reversed the migration and activation defects of RASGRP1-deficient lymphocytes.

RASGRP1 is a guanine-nucleotide-exchange factor that is involved in lymphocyte development and function1. The catalytic region of RASGRP1 consists of a RAS exchange motif and a CDC25 domain. RASGRP1 contains two atypical calcium-binding EF hands, a $\mathrm{C} 1$ diacylglycerol (DAG)-binding domain and a protein kinase $\mathrm{C}$ phosphorylation site that is necessary for activation of the protein2. Although the protein has high expression in lymphoid cells, its role is best studied in T cells following activation of the TCR2. Following increased DAG expression and/or phosphorylation by protein kinase C, RASGRP1 translocates to the membrane and converts the small GTPase RAS from an inactive GDPbound to an active GTP-bound state. This process mediates activation of the MAP-kinase (RAS-RAF-MEK-ERK) cascade3.

Although RAS signaling is well known for its association with malignant transformation, RAS GTPases control a variety of cellular processes under physiological conditions, including cell growth, differentiation, apoptosis, neuronal activity and cell migration. There 
are three main RAS isoforms ( $\mathrm{K}, \mathrm{H}$ and $\mathrm{N})$ that all share a conserved core GTPase domain but have distinct biological functions. Depending on the upstream stimulus, RASGRP1 can activate all three Ras isoforms4. Studies of Rasgrp $1^{-/-}$mice have revealed substantial defects in thymocyte development and function as a result of defective TCR-mediated ERK phosphorylation. Accordingly, Rasgrp $1^{-1-}$ mice have considerably fewer $\mathrm{CD} 4^{+}$and $\mathrm{CD} 8^{+} \mathrm{T}$ cells compared with wild-type mice5.

Studies of patients with inborn errors of their immune system (primary immunodeficiency disorders) have considerably shaped the molecular understanding of key nodes of human immunity, sometimes revealing surprising differences between patients and mouse models with deficiency in corresponding gene products6-8. In humans, the subgroup of quantitative or qualitative defects of $\mathrm{T}$ lymphocytes that result in combined immunodeficiencies comprise a heterogeneous subgroup of primary immunodeficiencies 9,10 . Often, these defects are associated with primary or secondary B cell defects11,12. Despite some heterogeneity, impairment of adaptive immunity in these diseases increases susceptibility to recurrent, earlyonset and severe infections with a variety of pathogens, including viruses, bacteria, fungi and parasites9.

We found that deficiency in human RASGRP1, a major regulator of RAS signaling in T lymphocytes, resulted in a previously unknown primary immunodeficiency disease. Our findings indicate a major role for RASGRP1 in immune cell signaling and function in T cells, B cells and NK cells. We also decipher a previously unknown role for RASGRP1 in the dynamic regulation of the cytoskeleton and identify lenalidomide as a potential treatment option for this immunodeficiency.

\section{Results}

\section{Identification of human RASGRP1 deficiency}

We studied a 12-year-old index patient of healthy consanguineous parents (Fig. 1a). Three older siblings of the patient (II/1, II/3 and II/4; Fig. 1a) died in the first 2 years of life, possibly as a result of immunodeficiency-related complications. However, no material from these siblings was available for further genetic testing. The index patient presented with recurrent infections, including multiple episodes of pneumonia that resulted in bronchiectasis and collapse of the right upper pulmonary lobe (Fig. 1b). Over time, severe failure to thrive, with height and weight below the third percentile, as well as finger clubbing became evident (data not shown). At the age of 12 years, after another episode of pneumonia, monthly intravenous immunoglobulin therapy was started. Prophylactic antibiotic therapy was recommended, which the patient did not use regularly. Further episodes of pneumonia and herpetic lesions necessitated hospitalization. Serial immunological analyses revealed normal numbers of total lymphocytes, but a progressive decrease in the number of $\mathrm{CD} 4^{+} \mathrm{T}$ cells, an inverted ratio of $\mathrm{CD} 4^{+} \mathrm{T}$ cells to $\mathrm{CD} 8^{+} \mathrm{T}$ cells, an increased relative proportion of TCR $\gamma \delta$ cells, and progressively decreasing B cell counts compared with healthy individuals (Fig. 1c and Supplementary Table 1). Routine adenotomy was performed on this patient at the age of 15 and, unexpectedly, histology revealed a lowgrade Epstein-Barr virus (EBV)-associated B cell lymphoma (Supplementary Fig. 1a). Given the immunodeficiency-related complications and the development of lymphoma, 
chemotherapy was performed, followed by myeloablative conditioning and allogeneic hematopoietic stem cell transplantation.

Given the known consanguinity in the family and the absence of clinical signs of immunodeficiency in either parent, paralleled by unremarkable leukocyte immunophenotyping (Supplementary Tables 2 and 3), we suspected an autosomal-recessive disease trait. We performed homozygosity mapping and exome sequencing to identify the underlying genetic disease etiology. Although we detected no variants in genes previously associated with primary immunodeficiencies, we found a homozygous nonsense variant on Chr15: 38805097: G>A (hg19 build 137) (c. C726T, p. Arg246*) in RASGRP1 (Fig. 1d,e). This variant has not been observed in heterozygous or homozygous form in several human genetic variation databases including the 1000 Genomes Project and the Exome Aggregation Consortium (ExAC) (Supplementary Tables 4 and 5a). It was predicted to be highly damaging for the corresponding protein function, with a combined annotation-dependent depletion (CADD) score of 35 (Supplementary Table 5b). The RASGRP1 gene has a negative residual variation intolerance score and is among the $11.77 \%$ most intolerant genes, indicative of the evolutionary conservation of RASGRP1. Accordingly, the number of 'observed' nonsense variants was significantly lower than the number of 'expected' nonsense variants (Supplementary Table 5b). Of note, no other homozygous variants in RASGRP1 leading to premature stop codons or frameshift mutations have been observed with higher population frequencies (Supplementary Table 5a). The variant showed perfect co-segregation with the disease under the assumption of autosomal-recessive inheritance, with both parents and all three available healthy siblings being heterozygous for the detected variant (Supplementary Fig. 1). In addition to the identified stop codon variant in $R A S G R P 1$, a variant in UROC1 (p.G313R), which encodes urocanase enzyme, segregated with the disease in the core family (data not shown). Biallelic loss-of-function mutations in this gene have been shown to cause urocanic aciduria, mental retardation and ataxia13. As we could not reconcile this variant with the immunodeficiency in our patient, we disregarded this gene as being causative of the immunological phenotype in the index patient.

To assess the effect of the variant in $R A S G R P 1$, we expressed wild-type or mutant streptavidin-hemagglutinin (Strep-HA)-tagged RASGRP1 in doxycycline-inducible HEK293T human embryonic kidney cells and observed markedly reduced expression of the truncated protein product (Fig. 1f). Consistent with these observations, immunoblot analysis with an antibody to RASGRP1 (anti-RASGRP1) did not detect endogenous full-length

RASGRP1 protein in cells from the patient (Fig. 1g).

\section{Profound multifaceted peripheral blood T cell defects}

Mouse studies have identified RASGRP1 as a guanine-nucleotide-exchange factor that acts as an essential activator of the RAS-RAF-MEK-ERK signaling in T cells; it thus serves as a major regulator of $\mathrm{T}$ cell development14, survival and proliferation15. Activation of RASGRP1 is dependent on DAG and occurs following activation of the signaling protein PLC $\gamma 1$ in T cells16. RASGRP1 has high expression in all lymphoid cells and in a variety of other cell types 17. However, so far the function of mouse RASGRP1 beyond its function in $\mathrm{T}$ cells has remained largely elusive (comparison, Supplementary Table 6). We performed 
detailed $\mathrm{T}$ cell immunophenotyping to characterize deficiency in human RASGRP1 and observed persistent $\mathrm{CD} 4^{+} \mathrm{T}$ cell lymphopenia together with an increase in the number of $\mathrm{CD} 8^{+} \mathrm{T}$ cells compared with healthy controls (Fig. 2a). Evaluation of the distribution of TCRa $\beta \mathrm{T}$ cells versus that of TCR $\gamma \delta \mathrm{T}$ cells revealed increased numbers of TCR $\gamma \delta^{+} \mathrm{CD} 8^{+}$ $\mathrm{T}$ cells compared to reference values (Supplementary Table 1). We further investigated the compartment of non-conventional $\mathrm{T}$ cells and observed reduced numbers of mucosalassociated invariant $\mathrm{T}$ cells (Supplementary Table 3). Furthermore, the number of invariant NKT cells was very low, bordering on absent (Supplementary Tables 3 and 6, and Supplementary Fig. 2), reminiscent of studies of mice18. Although a prominent population expressing the TCR $a$-chain variable region $24\left(\mathrm{~V}_{\mathrm{a}} 24\right)$ was detectable 19, these cells expressed the surface markers CD8 and CD45RA (Supplementary Fig. 2a), which suggested that they might belong to oligoclonally expanded and exhausted memory $\mathrm{CD} 8^{+} \mathrm{T}$ cells.

Both $\mathrm{CD}^{+}{ }^{+} \mathrm{T}$ cells and $\mathrm{CD} 8^{+} \mathrm{T}$ cells from the patient exhibited an exhausted phenotype, as indicated by expansion of $\mathrm{CCR}^{-} \mathrm{CD} 45 \mathrm{RA}^{+}$effector memory $\mathrm{T}$ cell populations, which represented up to $80 \%$ of $\mathrm{CD} 8^{+}$T cells (Fig. 2b,c, Supplementary Table 3 and Supplementary Fig. 3 ). In the $\mathrm{CD} 4^{+} \mathrm{T}$ cell subset, the majority of cells were CD45RA ${ }^{-} \mathrm{CXCR}^{+}$(Fig. 2d), suggestive of an increased frequency in peripheral blood follicular helper $\mathrm{T}$ cells compared with healthy controls5,20,21. In the CD $4^{+}$compartment of the patient, normal proportions of $\mathrm{CD} 25^{+} \mathrm{FOXP} 3{ }^{+} \mathrm{CD} 4^{+}$regulatory $\mathrm{T}$ cells and recent thymic emigrants were present (Supplementary Table 3).

Functionally, both RASGRP1-deficient $\mathrm{CD} 4^{+} \mathrm{T}$ cells and RASGRP1-deficient $\mathrm{CD} 8^{+} \mathrm{T}$ cells showed defective proliferation after stimulation with antibody to the TCR invariant chain CD3 (anti-CD3) and antibody to the costimulatory molecule CD28 (anti-CD28) (Fig. 2e and Supplementary Fig. 3), accompanied by impaired expression of the activation markers CD25 and CD69 (Fig. 2f). Defective T cell proliferation was recapitulated in Jurkat human T cells with doxycycline-inducible short hairpin RNA-based knockdown of RASGRP1 (shRASGRPI) (Supplementary Fig. 2b). In addition, proliferation assays using thymidine incorporation also showed defective cellular proliferation after nonspecific stimulation with various mitogens (Supplementary Fig. 2c). Consistent with the above-mentioned proliferation defects, TCR $\mathrm{V}_{\beta}$ spectratyping of patient peripheral blood $\mathrm{T}$ cells revealed a restricted TCR repertoire (Fig. $2 \mathrm{~g}$ and Supplementary Fig. $2 \mathrm{~d}$ ). CD8 ${ }^{+}$cytotoxic T cell populations obtained from the patient and expanded ex vivo showed increased expression of perforin and granzyme B compared to healthy donors (Fig. 2h), as well as defective killing of targets cells following activation with the monoclonal antibody against CD3 (OKT-3) (Fig. 2i).

Published studies have shown that RASGRP1 is critical for TCR-induced signal transduction in mouse $\mathrm{T}$ cells 5,16 . Here we sought to investigate the functional consequences of RASGRP1 deficiency on the activation of human T cells. In both inducible shRASGRP1Jurkat cells and in a patient $\mathrm{T}$ cell line, immortalized using human telomerase reverse transcriptase (hTERT) we did not observe defects in initial TCR signaling events upstream of RASGRP1, including intercellular adhesion molecule 1 (ICAM1) ring formation, exclusion from the central supramolecular activation complex (cSMAC), or calcium flux (Fig. $2 \mathrm{j}$ and Supplementary Fig. 2e-g). Thus, we focused on potential signaling defects 
downstream of RASGRP1 in populations of primary peripheral blood mononuclear cells (PBMCs) obtained from patient and expanded ex vivo using anti-CD3 and anti-CD28. Cells were serum- and antibody-starved and re-stimulated with anti-CD3 and anti-CD28. We observed reduced, but not absent, phosphorylation of ERK1/2 (at Thr202 and Tyr204) in RASGRP1-deficient cells compared to healthy donor expanded T cells (Fig. 2k,1 and Supplementary Fig. 2h). Transient transfection of the cells with vector encoding wild-type RASGRP1 normalized impaired activation of ERK in the patient's CD8 ${ }^{+} \mathrm{T}$ cells (Fig. $2 \mathrm{~m}$ ).

\section{Deficient B cell activation and proliferation}

Studies of the role of RASGRP1 in mouse B cells have remained contradictory22,23. We performed detailed immunophenotypic analysis of the patient's B cell subsets and observed decreased proportions of memory B cells $\left(\mathrm{CD} 19^{+} \mathrm{CD} 27^{+}\right)$and increased proportions of both transitional B cells and CD21 ${ }^{\mathrm{lo}} \mathrm{B}$ cells, the latter of which consituted up to $20 \%$ of all $\mathrm{CD} 19^{+} \mathrm{B}$ cells, compared to healthy donor B cell subsets (Fig. 3a,b and Supplementary Fig. 3). The concentrations of total immunoglobulin $\mathrm{G}(\operatorname{IgG})$ and $\operatorname{IgM}$ were normal in the patient, but IgA concentrations were elevated (Supplementary Table 1). Although findings from mouse studies have suggested a role for RASGRP1 in the development of autoimmunity 22 and genome-wide association studies have identified an association of single-nucleotide variants in the gene encoding RASGRP1 with systemic lupus erythematodes24, no clinical signs of autoimmunity were apparent, consistent with the absence of detectable autoantibodies (Supplementary Table 7). However, we observed insufficient vaccination responses, including absent antibodies to hepatitis B surface antigen and decreased pneumococcusspecific antibodies following vaccination (data not shown).

To assess B cell function, we stimulated the patient's PBMCs with antibody to the costimulatory receptor CD40 and interleukin 4 (IL-4)25. The patient's B cells, compared to healthy donor $\mathrm{B}$ cells, showed reduced upregulation of expression of the activation markers CD86, CD25, CD95 and CD69 (Fig. 3c) that resulted in decreased B cell proliferation (Fig. 3d) and reduced class-switch recombination following stimulation (Fig. 3e). The observed defects could not be reversed by the addition of the mature B cell survival factor BAFF (Fig. 3f), which suggested that self-reactive transitional B cells were absent from the PBMC compartment 26 .

Both quantitative defects and qualitative defects in B cells in patients with inherited deficiencies of $\mathrm{T}$ cells result from either an intrinsic $\mathrm{B}$ cell defect (primary defect) or deficient co-stimulation11,12. To assess our hypothesis of a B cell-intrinsic phenotype, we evaluated $\mathrm{B}$ cell antigen receptor (BCR) signaling in EBV-transformed B cell lines from the patient. The EBV-immortalized B cells showed reduced activation of the MAPK pathway following IgM stimulation, similar to the T cell defects that we observed (Fig. 3g). Defective ERK phosphorylation in patient $\mathrm{B}$ cells was reversed after lentiviral transduction of wildtype RASGRP1 (Fig. 3h). Collectively, the patient's B cells showed defective MAPK activation, with defective BCR signaling resulting in reduced proliferation and class switching. 


\section{RASGRP1 deficiency causes impaired NK-cell cytotoxicity}

Mouse studies have not yet addressed the role of RASGRP1 in NK cells, to the best of our knowledge. We observed unaltered numbers of the patient's NK cells with normal CD56 ${ }^{\mathrm{dim}}$ and CD56 $6^{\text {bright }}$ subset distributions (Supplementary Table 1). However, the CD56 $6^{\text {bright }}$ NK cells had high expression of intracellular IL-5 (Supplementary Fig. 4a). These data might suggest that there is a developmental bias toward the production of $\mathrm{T}$ helper type 2 cytokines at an intermediate differentiation state, as production of these cytokines is lost following terminal differentiation27. Despite having high protein expression levels of intracellular granzyme B and perforin (Fig. 4a), the patient's NK cells exhibited severely impaired cytolytic function (Fig. 4b). This impairment was associated with defective formation of a mature NK cell immunological synapse in CRISPR/Cas9-edited NK-92 cell lines deficient in RASGRP1 ( $\mathrm{sg} R A S G R P I)$ (Fig. 4c) with decreased F-actin accumulation, increased distance from the microtubule-organizing center (MTOC) to the synapse and impaired granule convergence (Fig. 4d-f), consistent with impaired formation of the NK cell immunological synapse in primary cells from the patient (Supplementary Fig. 4b).

\section{Proteomics links RASGRP1 to cytoplasmic dynein}

The patient's CD8 ${ }^{+} \mathrm{T}$ cells displayed normal expression of ICAM1 and did not show any defects in ICAM1 ring formation or exclusion from the central supramolecular activation complex following TCR stimulation (Supplementary Fig. 2f), which suggested that the cells retained the required elements for formation of the immunological synapse. In addition, the patient's NK cells showed normal expression of NK cell-activating receptors, as well as similar levels of granzyme B and perforin protein expression compared to healthy donor NK cells (Fig. 4a). However, we observed an unusual combination of defective granule convergence together with defects in the accumulation of $\mathrm{F}$ actin in both the patient's NK cells and $\operatorname{sg} R A S G R P 1$ NK-92 cells. Assuming a similar role for MAPK activation in actin polymerization in both $\mathrm{T}$ cells and NK cells 28 , we hypothesized that the defect in granule convergence might be linked to an as-yet-unknown interaction partner. Thus, we performed tandem affinity purification of RASGRP1 tagged at the amino terminus with Strep-HA plus subsequent mass-spectrometry analysis of bound interactors in HEK293T cells and Jurkat T cells (Fig. 4g). In both HEK293T cells and Jurkat T cells which were engineered for doxycycline-inducible RASGRP1 expression, the dynein light chain DYNLL1 was one of the top-ranking interacting proteins according to both SAINT and FC-scoring (Fig. 4g). Notably, published studies of mice and rats have reported binding of RASGRP3, but not of RASGRP1, to DYNLL1 (ref. 29). Such cross-species differences might be explained by the fact only human RASGRP1 contains a binding motif similar to that of mouse RASGRP3 (ref. 30) (Fig. 4h). Co-immunoprecipitation of RASGRP1 tagged at the amino terminus with Strep-HA confirmed the interaction of RASGRP1 with endogenous DYNLL1 in both Jurkat T cells and HEK293T cells (Fig. 4i, Supplementary Table 8a,b and Supplementary Fig. 4d). Substitution of the assumed DYNLL1-binding motif with alanine residues resulted in abrogation of the binding of DYNLL1 (Fig. 4i), which confirming the critical role of this motif in the RASGRP1-DYNLL1 interaction.

Cytoplasmic dynein can mediate retrograde transport over the microtubule cytoskeleton toward the MTOC in T cells, which results in centrosome polarization following TCR 
activation31. In NK cells, dynein-driven transport of lytic granules along microtubules is required for convergence to the MTOC preceding formation of the immunological synapse32. Visualization of $\mathrm{sg} R A S G R P 1 \mathrm{NK}$ cells by video microscopy revealed markedly defective granule motility (Fig. 4j,k). Consistent with a putative role for RASGRP1 in regulating the microtubule cytoskeleton, accumulation of dynein before centrosome polarization has been shown to depend on the RASGRP1 activator DAG33. Moreover, lytic granule convergence occurs rapidly after target-cell engagement and is independent of actin dynamics32. Thus, RASGRP1 deficiency markedly affects NK cell cytotoxicity by impairing both actin polymerization and the convergence of lytic granules to the MTOC, which is possibly explained by an abrogated interaction with DYNLL1.

\section{Reversal of cellular defects by lenalidomide}

Apart from NK-cell cytotoxicity, microtubules and actin also depend on precisely coordinated interactions to establish cell polarity 34 and the coordinated cell migration that is essential for lymphocyte function34. To visualize cytoskeletal dynamics and cell migration in primary cells from the patient, we transiently transfected $\mathrm{CD} 8^{+} \mathrm{T}$ cells with the actin marker Lifeact ${ }^{\mathrm{TM}}$. We observed significantly slower actin turnover in RASGRP1-deficient $\mathrm{CD}^{+} \mathrm{T}$ cells than in $\mathrm{CD} 8^{+} \mathrm{T}$ cells from healthy donors (Fig. 5a,b). To assess whether slow actin turnover would also 'translate' into a low cell-migration speed, we performed cellmigration assays with $\mathrm{CD} 8^{+} \mathrm{T}$ cells stimulated with the chemokine CXCL12 on ICAM-1coated plates. Indeed, RASGRP1-deficient cells migrated at lower speeds than did CD8 ${ }^{+} \mathrm{T}$ cells from healthy donors (Fig. 5c).

RASGRP1-deficient mouse mast cells display decreased RhoA activity35. We found that levels of active RhoA were markedly lower in the patient's T cells following CXCL12 stimulation compared with healthy donor T cells, whereas total RhoA levels differed only mildly (Supplementary Fig. 5). Thus, we hypothesized that activation of RhoA signaling might reverse the migration defect of RASGRP1-deficient $\mathrm{CD} 8^{+} \mathrm{T}$ cells. Indeed, the known RhoA activator nocodazole normalized the observed migration defect (Fig. 5d). However, as nocodazole is not amenable for clinical use, we sought to identify an alternative compound that could induce similar functional effects. In patients with chronic lymphocytic leukemia, T cells exhibit an exhausted (immunodeficient) phenotype that is similar to that of the RASGRP1-deficient patient36,37. The thalidomide-derived drug lenalidomide can modulate the activity of key transcription factors that are important for restoring $\mathrm{T}$ cell function, which results in increased RhoA activity38. Indeed, treatment with lenalidomide significantly increased cell velocity and thus normalized the overt migration defect observed in RASGRP1-deficient PBMCs (Fig. 5e); thus, this might represent a potential treatment option for RASGRP1-deficient patients. Consistent with the published positive effect of lenalidomide on IL-2 secretion39, we observed increased CD25 expression in T cells following lenalidomide treatment (Fig. 5f). Given that lenalidomide modifies multiple targets of the Cullin-E3 ligase complex by binding to its intracellular target cereblon, we aimed to investigate whether the effect of lenalidomide on the cellular phenotype could be linked to normalization of RhoA signaling. In $\mathrm{CD} 8^{+} \mathrm{T}$ cells from healthy control donors, stimulation with CXCL12 activated RhoA, as detected with an antibody specific for the GTP-bound state of RhoA (Fig. 5g,h). In contrast, CD8 ${ }^{+} \mathrm{T}$ cells from the RASGRP1- 
deficient patient failed to activate RhoA following stimulation with CXCL12 (Fig. 5g,h). Notably, treatment of the patient's $\mathrm{CD} 8^{+} \mathrm{T}$ cells with additional lenalidomide restored active RhoA to amounts comparable to those measured in the control CD8 ${ }^{+} \mathrm{T}$ cells (Fig. $5 \mathrm{~g}, \mathrm{~h}$ ).

\section{Discussion}

We identified human RASGRP1 deficiency as a previously unknown primary immunodeficiency with notable defects in the lymphoid compartment that were amenable to partial reversal with lenalidomide. Although our study was performed on a pedigree with a single affected patient, our results demonstrated that the loss of RASGRP1 caused the phenotype, consistent with outlined criteria as published40: the patient's candidate genotype was monogenic and did not occur in subjects without the clinical phenotype; we found that the detected mutation caused the absence of full-length RASGRP1 protein and reduced ERK phosphorylation; we observed restoration of the defective phosphorylation of ERK following expression of wild-type RASGRP1 in the patient's cells; and shRNA and CRISPR-based studies of Jurkat cells and NK-92 cell lines reproduced the phenotype observed in primary cells from the patient. The phenotype of human RASGRP1 deficiency differs substantially from previously described mouse models5,22 and suggests a previously unknown role for RASGRP1 in cellular responses beyond TCR signaling. Although RASGRP1-deficient mice exhibit decreased numbers of both $\mathrm{CD} 4^{+}$and $\mathrm{CD}^{+}$single-positive thymocytes5, the patient's immunological phenotype showed an inverted ratio of $\mathrm{CD}^{+}{ }^{+} \mathrm{T}$ cells to $\mathrm{CD} 8^{+} \mathrm{T}$ cells with population expansion of exhausted effector memory cells, consistent with a partial $\mathrm{T}$ cell defect 9 . Partial $\mathrm{T}$ cell defects are often associated with autoimmunity9. The role of RASGRP1 in autoimmunity has remained controversial. Both RASGRP1-deficient mice22 with an autoreactive BCR and Rasgrp $1^{-1-}$ mice overexpressing a truncated form of RASGRP1 that lacks the carboxy-terminal tail domain41 develop a lymphoproliferative disorder with features reminiscent of human systemic lupus erythematosus. We did not observe overt autoimmunity in human RASGRP1 deficiency. Future studies, including more RASGRP1-deficient subjects, will enable delineation of the full phenotypic spectrum of human RASGRP1 deficiency.

The role of RASGRP1 in NK cells has not been addressed in detail in mouse models. NK cells are innate immune cells best known for their ability to mediate cytotoxicity after the ligation of germline-encoded activation receptors42. A variety of human primary immunodeficiencies are associated with defective accumulation of actin at the immunological synapse, particularly actin-polymerization deficiencies such as WiskottAldrich syndrome 43 or deficiency in the actin regulators WIP44 or DOCK8 (ref. 45). However, the combination of defective polymerization of actin, together with the considerable granule-convergence defect seen in cells from the RASGRP-deficient patient has not been seen in human immunodeficiencies before, to our knowledge.

Accumulation of dynein before centrosome polarization in lymphocytes depends on the known RASGRP1 activator DAG46. Evidence has revealed a RAS-binding domain in the dynein intermediate chain that probably mediates activation of the complex47. Our discovery of an interaction between human RASGRP1 and cytosolic DYNLL1 provides evidence that RASGRP1 mediates granule convergence following activation, a dynein- 
dependent process 32 . To our knowledge, RASGRP1 deficiency represents the first association of impaired dynein function with a human primary immunodeficiency. Of note, several viral proteins, including the HIV-1 integrase, interact with DYNLL1, and their interaction has been shown to be involved in efficient reverse transcription of HIV-1 (ref. $48)$.

Our study has also identified a targeted treatment strategy with lenalidomide, providing proof-of-concept for such approaches in primary (and potentially secondary) immunodeficiencies with aberrant cytoskeletal dynamics. Thus far, the thalidomide derivative lenalidomide has been approved for various lymphoid malignancies, such as multiple myeloma37 and chronic lymphocytic leukemia36. In these diseases, $\mathrm{T}$ cells are in a state of pseudo-exhaustion and show defects in activation, proliferation and cytotoxicity49, similar to those observed in RASGRP1 deficiency. The action of lenalidomide has been linked to cereblon which, together with the scaffolding protein CUL4 and the catalytic subunit ROC1, forms the E3 ubiquitin ligase cereblon-CRL4 complex that mediates degradation of the transcription factors Ikaros and Aiolos and may alter other targets of the E3 ubiquitin ligase38. These processes result in, among other effects, the upregulation of RhoA activity, which might be the factor responsible for the rescue of RASGRP1-deficient lymphocytes36; we found that treatment with lenalidomide significantly increased RhoA activity in patient $\mathrm{CD} 8^{+} \mathrm{T}$ cells. In sum, we have identified RASGRP1 deficiency as a previously unknown type of partial $\mathrm{T}$ cell defect, which revealed a previously unknown link between RAS signaling and cytosolic dynein dynamics and which was amenable to improvement following RhoA activation and lenalidomide treatment.

\section{Online Methods}

\section{Patient and ethics}

The patient was included with informed written consent by the parents and approval from the Institutional Review Boards of the Medical University of Vienna and Ankara Hacettepe University Medical School.

\section{Homozygosity mapping}

Affymetrix 6.0 single nucleotide polymorphism (SNP)-based homozygosity mapping was performed as previously described50.

\section{Exome sequencing}

DNA extraction, exome sequencing and data analysis were performed as described previously50.

\section{Sanger sequencing}

Primers for the variants detected with exome sequencing were designed using PrimerZ. PCR amplification and capillary sequencing was performed as previously described51. 


\section{Statistics}

Statistical tests used in this study include Student's $t$ test, with or without Welch's correction, as appropriate and detailed in the respective methods sections.

\section{Mutational profile and population genetics}

The Combined Annotation Dependent Depletion (CADD) score was determined using CADD version v1.3 (ref. 52). The mutational and population genetics profile of RASGRP1 CCDS (ENSG00000172575) was obtained from ExAC (http://exac.broadinstitute.org/gene/ ENSG00000172575, accessed 29th April, 2016). The Residual Variation Intolerance Score was obtained from Genic Intolerance (http://genic-intolerance.org, accessed April 29, 2016). A binomial test was used to assess statistical significance of the deviation of the theoretically expected distribution of nonsense variants (expected) from the observed nonsense variants (observed) based on the ExAC database. Loss-of-function carrier frequency (q) was calculated as: $q=$ (SUM of putative loss-of-function population alleles)/(Total population alleles). Expected rate of nullizygous ( 1 in $X$ non-consanguineous conceptions) variants was calculated as: $X=1 / q^{2}$. If the Sum of putative loss of function alleles was $0, q^{\star}$ was calculated as: $q^{*}=1 /($ Total population alleles), and expected rate of nullizygous variants: $X$ $=1 /\left(q_{-}{ }^{\star 2}\right)$.

\section{Flow cytometry}

All flow cytometric analyses were recorded on a BD LSR Fortessa except NK-cell immunophenotyping (recorded on both BD LSR Fortessa and FACS Canto) and cell proliferation assays upon shRNA-mediated knockdown (recorded on BD FACS Calibur). All data were analyzed using FlowJo X (TreeStar) and data was graphed with Prism 6.0 (GraphPad Software).

\section{Immunophenotyping}

PBMCs immunophenotyping was performed on an LSR-Fortessa (BD Biosciences). Antibodies were used as described previously51 apart from: GranzymeB-AF700, TCRa $\beta$ FITC, TCRa $\beta$-PE, TCR $\gamma \delta$-APC, TCR $\gamma \delta$-PE, TCR-PE, all from BD Biosciences; TCR Va 7.2-APC, Ig-PE both from Miltenyi Biotec; Perforin-AF647 from BioLegend; CXCR5APC from Biomedica.

\section{Cell lines}

Feeder cell-mediated T-cell expansion-Feeder T-cell generation was done as described53,54. Obtained expanded T cells were evaluated by) flow cytometry for expression of $\mathrm{CD} 4, \mathrm{CD} 8$, perforin and granzyme $\mathrm{B}$ and purified as necessary using a MagniSort CD8 cell separation kit (eBioscience).

Generation of EBV-immortalized B-cell lines-Patient and healthy donor PBMCs were isolated using Ficoll density centrifugation. $10^{6}$ freshly isolated PBMCs were incubated with EBV virus supernatant and on the following day $1 \mu \mathrm{g} / \mathrm{ml}$ cyclosporin A was added to the cells. Cells were maintained in complete RPMI medium (Gibco) with $10 \%$ FCS, 1\% L-glutamine and 1\% PenStrep (all from Invitrogen). 
HEK293T cells-Human RASGRP1 cDNA and the mutant version thereof were cloned into pTO-SII-HA-GW vectors using gateway recombination to generate $\mathrm{N}$-terminal Streptavidin-Hemagglutinin-tagged fusion protein and transfected into HEK293 Flp-InTREx cells (Thermo Fisher Scientific) as described55,56.

Jurkat cells with inducible overexpression of RASGRP1-Jurkat E6.1 cells (ATCC) were retrovirally infected with a retroviral vector (MSCV-rtTA3-IRES-EcoR-PGKPuro) as described previously57,58. A codon-optimized version of RASGRP1 cDNA (IDT systems) was cloned into pSIN-TREtight-SH-gw-N-IRES-mCherry-PGK-BlastR as described57.

Inducible shRNA mediated knock down of RASGRP1 in Jurkat cells-Short hairpin RNAs were designed according to published recommendations57. Jurkat T-cell line expressing an rtTA3 element with an ecotropic receptor as well as PlatE cells for virus production were kindly provided by Johannes Zuber (IMP). Cell lines were tested for protein expression $24 \mathrm{~h}$ after induction with $1 \mu \mathrm{g} / \mathrm{ml}$ doxycycline using flow cytometric analyses. GFP marks successful transfection whereas dsRed expression indicates protein expression after doxycycline addition. The following short hairpin RNAs were used:sh_RGRP1:UGAAACACUAACUACAAGCUA;sh_RGRP2:

UUAACUUGUAUACUAUACCUC. Each shRNA has 2 off-targets sites that correspond to known RASGRP1 isoforms and no Xhol/EcoRI restriction sites.

CRISPR-mediated gene deletion in NK-92 cell lines-CRISPRs targeting RASGRP1 were designed as described59 and cloned into a lentiCRISPRv2 vector60. NK-92 cells (ATCC) were cultivated according to the supplier's instructions. Lentiviral virus production and cell infection were performed according to standard procedures. Limited dilution was performed and single cell clones were selected. Editing at genomic position was confirmed using capillary sequencing and subsequent upload into tide (http://tide.nki.nl/, accessed November, 2014)61. Only clones with frameshift mutations in both alleles of more than $90 \%$ were used for further experiments. Following CRISPR targeting sequences were used for cloning: C_RASGRP1_E2_p1_A_t:CACCgAGACACCATCATTCGGAACT; C_RASGRP1_E2_p1_A_b:AAACAGTTCCGAATGATGGTGTCTc; C_RASGRP1_E2_p2_A_t:CACCgGAGACACCATCATTCGGAAC; C_RASGRP1_E2_p2_A_b:AAACGTTCCGAATGATGGTGTCTCc.

\section{Immunoblot experiments}

RASGRP1 immunoblot experiments- $4 \times 10^{6}$ Patient and healthy donor EBVimmortalized B cells were lysed in $50 \mu \mathrm{L}$ Laemmli Buffer, ran on a $10 \%$ acrylamide gel at $110 \mathrm{~V}$ and blotted overnight at $120 \mathrm{~mA}$ at $4{ }^{\circ} \mathrm{C}$ on a PVDF membrane. Membranes were incubated with anti-human RASGRP1 (Merck Millipore, Clone 10.1) in Tris-buffered saline with $0.5 \%$ Tween and $5 \%$ milk overnight at $4{ }^{\circ} \mathrm{C}$ and a secondary anti-mouse antibody at $\sim 21^{\circ} \mathrm{C}$ for $2 \mathrm{~h}$. Blots were developed using ECL (Thermo Scientific) and films (GE healthcare). 
TCR and BCR signaling analysis-Patient or healthy donor derived T-cell lines were starved for up to $4 \mathrm{~h}$ in RPMI medium (Invitrogen) containing 1\% FCS (Sigma-Aldrich), 0.2 $\mathrm{mM} \mathrm{L-glutamine} \mathrm{(Sigma-Aldrich),} 10 \mu \mathrm{g} / \mathrm{ml}$ penicillin/streptomycin (Sigma-Aldrich and 20 $\mathrm{mM}$ HEPES (Gibco). Cells were put on ice for at least $20 \mathrm{~min}$ and ice-cold stimulation mix containing $\mathrm{mAb}$ to $\mathrm{CD} 3$ (clone OKT-3, purified, $2 \mu \mathrm{g} / \mathrm{ml}$ ) and $\mathrm{mAb}$ against CD28 (clone Leu28, purified, $1 \mu \mathrm{g} / \mathrm{ml}$, BD Bioscience). Cells were stimulated for indicated time points, washed in ice-cold PBS and lysed in $20 \mathrm{mM}$ Tris- $\mathrm{HCl}$ (pH 7.5), $150 \mathrm{mM} \mathrm{NaCl}, 2 \mathrm{mM}$ EDTA (all from Roth) and complete protease inhibitor tablets (Roche), $1 \mu \mathrm{M}$ orthovanadate, $50 \mathrm{mM}$ NaF, $1 \%$ Triton X-100 (Thermo Scientific). Upon addition of Laemmli buffer samples were boiled for 5 min and loaded on 8 or $10 \%$ acrylamide gels. Gels were run at constant voltage and blotted over night with constant $120 \mathrm{~mA}$ at $4{ }^{\circ} \mathrm{C}$ using a mini-protean wet blotting system (BioRad). Immunoblotting was performed according to standard conditions with Tween-buffered saline and 5\% bovine serum albumin (Roth) according to the manufacturer's instructions. Antibodies are summarized below.

Prior to stimulation, B cells were serum starved for 3-4 h and stimulated with anti-IgM 500 $\mathrm{ng} / \mathrm{ml}$ (Southern Biologicals) for the indicated time points. Subsequent handling was performed as described for TCR signaling analyses: p44/42 MAPK (ERK1/2) (clone 137F5), Phospho-p44/42 (Thr202/Tyr204) MAPK (ERK1/2), (clone D13.14.4E; all from Cell Signaling), GAPDH (clone 86C5, Santa Cruz Biotechnology).

\section{Tandem affinity purification and mass spectrometry analyses}

Tandem affinity purification and mass spectrometry analyses were performed as described62. Data were uploaded to CRAPome database for FCA, FCB and Saint score calculations63.

\section{Co-immunoprecipitation of RASGRP1 and DYNLL1 in HEK293 cells and Jurkat} T cells-Immunoprecipitation was performed by lysing induced cells in IP buffer $(50 \mathrm{mM}$ HEPES pH 8.0, $150 \mathrm{mM} \mathrm{NaCl}, 5 \mathrm{mM}$ EDTA, 0.5\% NP-40, $50 \mathrm{mM} \mathrm{NaF}, 1 \mathrm{mM} \mathrm{Na}_{3} \mathrm{VO}_{4}$, protease inhibitors from Sigma-Aldrich). Lysates were precleared with Protein G-Sepharose beads (GE Healthcare) and tagged RASGRP1 protein purified using anti-HA agarose beads (Sigma-Aldrich). Immunoprecipitates were washed with wash buffer (50 mM HEPES pH 8.0, $300 \mathrm{mM} \mathrm{NaCl}, 5 \mathrm{mM}$ EDTA, $1 \% \mathrm{NP}-40,50 \mathrm{mM} \mathrm{NaF}, 1 \mathrm{mM} \mathrm{Na}_{3} \mathrm{VO}_{4}$, protease inhibitors from Sigma-Aldrich), and analyzed by SDS-PAGE separation, blotting and immunostaining using antibodies against DYNLL1, GAPDH (both Santa Cruz Biotechnology) and HA tag (Sigma-Aldrich; 1:1,000 dilution for DYNLL1 antibody and 1:2,000 dilution for others). 1/40 of the lysate used for immunoprecipitation was used as input control.

\section{T-cell proliferation}

Thymidine incorporation assays were performed as described51. Flow cytometry-based proliferation assays were performed using Violet proliferation dye 450 (BD Biosciences). In brief, cells were labeled with proliferation dye according to manufacturer's instructions and incubated with stimulating antibodies $1 \mu \mathrm{g} / \mathrm{ml}$ anti-CD3 (clone OKT3/Leu-4, T3, eBiosciences) and $0.5 \mu \mathrm{g} / \mathrm{ml}$ anti-CD28 (clone T44, CD28.2, eBiosciences) for up to $4 \mathrm{~d}$. 
Proliferation of shRNA-transfected Jurkat T-cell lines was performed by labeling cells with V450 proliferation dye and subsequent knockdown induction with $1 \mu \mathrm{g} / \mathrm{ml}$ doxycycline. For proliferation studies samples were taken on consecutive days and analyzed by flow cytometry after staining with additional markers (see Immunophenotyping section).

\section{Flow-cytometry-based T-cell cytotoxicity}

Assays to quantify the cytotoxic activity of $\mathrm{CD} 8^{+} \mathrm{T}$ cells were done as previously described with minor modifications64. In brief, GFP-expressing P815 target cells were treated with aphidicolin to inhibit proliferation and pre-incubated either with or without OKT-3 (1 $\mu \mathrm{g} /$ $\mathrm{ml})$. Different ratios of target cells and $\mathrm{CD}^{+} \mathrm{T}$ cells were distributed in 96-well U-bottom low-cell-binding plates (Nunc). Following 6 or $24 \mathrm{~h}$ of incubation, cells were stained with 7$\mathrm{AAD}$ and residual alive target cells were evaluated.

\section{T-cell and B-cell reconstitution experiments}

T cells-Patient and healthy donor PBMCs were thawn and transfected with a GFP control or wild-type N-terminally GFP-tagged RASGRP1 using the Amaxa human T-cell nucleofector kit (Lonza) and program V024 (unstimulated T cells). Cells were rested for $1 \mathrm{~d}$ in complete IMDM, starved for $4 \mathrm{~h}$ in serum-free medium and stimulated for 30-40 min with stimulating antibodies $1 \mu \mathrm{g} / \mathrm{ml}$ anti-CD3 (clone OKT3/Leu-4, eBiosciences) and 0.5 $\mu \mathrm{g} / \mathrm{ml}$ anti-CD28 (Clone T44, CD28.2, eBiosciences). Cells were fixed in $100 \mu \mathrm{l}$ IC-Fixation solution (eBioscience) for 20-60 min, washed 2x in Fixation/Permeabilization buffer (eBioscience) and stained with antibodies against pERK, CD4, CD8 and CD3 (see Flow Cytometry section) for $1 \mathrm{~h} \sim 21{ }^{\circ} \mathrm{C}$. Samples were washed in $1 \mathrm{x}$ in Fixation/Permeabilization buffer and $1 \times$ in PBS and analyzed by flow cytometry gating on GFP-positive cells.

B cells-Patient and healthy donor B-cell lines were transduced using a lentiviral vector (pRRL_EF1a_StrepHA_IRES_GFP), with second generation packaging plasmids (PAX2 and MD2G) kindly provided by the Giulio Superti-Furga laboratory (CeMM). For phosphoERK analyses, transduced B-EBVs were serum-starved for $2-3 \mathrm{~h}$ and stimulated using IgM antibody (Southern biologicals) for 30-40 min. Staining was performed as described for T cells with pERK and CD19.

\section{B-cell class switch recombination}

B-cell class switch recombination (CSR) experiments were performed on freshly isolated PBMCs. Cells were labeled with Violet proliferation dye 450 (BD Biosciences) according to manufacturer's instructions and seeded into a 96-well plate at $2 \times 10^{5}$ cells/well in IMDM medium supplemented with 10\% FCS, 5\% L-Glutamine, penicillin/streptomycin, $1 \%$ HEPES and beta-mercaptoethanol. B-cell proliferation and CSR were induced using CD40L (1/800 dilution of the titrated supernatant and IL-4 (30 ng/ml) or CD40L/IL-4/BAFF (1/1,000 dilution of the titrated supernatant; both kindly provided by $\mathrm{H}$. Eibel, Center for Chronic Immunodeficiency) for $4 \mathrm{~d}$. The activation status of the cultured B cells was measured $1 \mathrm{~d}$ upon induction by flow cytometry using CD19, CD86, CD25, CD69 and CD95 antibodies. Cell proliferation was measured by monitoring the dilution of the proliferation dye, and CSR by monitoring IgG expression on the surface on $\mathrm{CD} 19^{+} \mathrm{B}$ cells using flow cytometry after $4 \mathrm{~d}$ in culture. 


\section{Cell migration assays following lenalidomide treatment}

Agarose based assays-Human $\mathrm{CD} 8^{+} \mathrm{T}$ cells were purified using MagniSort Human CD8 ${ }^{+}$T-cell Enrichment Kit (eBioscience) and labeled with $5 \mu \mathrm{M}$ CMTMR (Invitrogen) $1 \mathrm{~d}$ before imaging and incubated with $1 \mu \mathrm{M}$ lenalidomide or DMSO for $24 \mathrm{~h}$, and recorded migrating confined under agarose block. Briefly, home-made glass bottom dishes were coated with $2 \mu \mathrm{g} / \mathrm{ml}$ human ICAM-1 Fc (R\&D) at $4{ }^{\circ} \mathrm{C}$ overnight and afterwards rinsed with PBS to remove residual, unbound protein. $500 \mu \mathrm{l}$ of $0.5 \%$ agarose (Biozym Gold Agarose) solution containing $100 \mathrm{ng} / \mathrm{ml}$ human CXCL12 (R\&D), $50 \mu \mathrm{M}$ ascorbic acid and fully supplemented R10 medium (RPMI 1640, 10\% FCS, glutamine, non-essential amino-acids, $\beta$-mercaptoethanol) were poured onto the coated dishes to form approximately 3-mm thick layer and allowed to solidify for $1 \mathrm{~h}$ at $4{ }^{\circ} \mathrm{C}$. Finally, dishes were equilibrated for $30 \mathrm{~min}$ in a humidified incubator at $37^{\circ} \mathrm{C}, 5 \% \mathrm{CO}_{2}$ and cells were injected between the glass and the agarose layer. Cells were recorded at $37{ }^{\circ} \mathrm{C}$ on Nikon Eclipse Ti inverted microscope equipped with Hamamatsu EMCCD C9100-02 camera and tracked using Volocity software (PerkinElmer).

Video microscopy without agarose-The experiment was carried out as described 36 . Stimulation of PBMCs with $1 \mu \mathrm{M}$ lenalidomide or DMSO was performed for $20 \mathrm{~h}$ before microscopy.

\section{Actin retrograde flow assay}

Isolated human $\mathrm{CD} 8^{+} \mathrm{T}$ cells were nucleofected with plasmid expressing Lifeact-GFP using Nucleofector II and Mouse T-cell Nucleofector Kit (Lonza) $1 \mathrm{~d}$ before imaging. Glass bottom dishes (MatTek) were coated with $0.2 \mathrm{mg} / \mathrm{mL}$ PLL-PEG at $4{ }^{\circ} \mathrm{C}$ overnight and afterwards rinsed with PBS to remove residual PLL-PEG. $500 \mu$ of $0.5 \%$ agarose (Biozym Gold Agarose) solution containing $100 \mathrm{ng} / \mathrm{ml}$ human CXCL12 (R\&D) were poured onto the coated dishes. Cells were injected between the glass and the solidified agarose layer as described above.

Total internal reflection (TIRF) microscopy was performed at $37^{\circ} \mathrm{C}$ with an inverted Axiovert 200 (Zeiss) microscope, a TIRF 488/561-nm laser system (Visitron systems) and an EvolveTM EMCCD camera (Photometrics) triggered by VisiView software (Visitron). FIJI image processing package was used for image and kymograph analysis.

\section{Protein expression and lipid bilayers}

DNA constructs for production of monovalent streptavidin (MonoSAv) were a gift from A. Ting (Massachusetts Institute of Technology). A 3C protease-recognition sequence was inserted between the alive streptavidin subunit and the six-glutamate tag. The gene encoding the dead streptavidin subunit was prolonged with a six-histidine tagged tail mediating binding to supported lipid bilayers containing 18:1 DGS-NTA(Ni) (1,2-dioleoyl-snglycero-3-[(N-(5-amino-1-carboxypentyl) iminodiacetic acid)succinyl] (nickel salt)65. MonoSAv was produced by an in vitro refolding protocol as described66,67 and subsequently purified by MonoQ (MonoQ 5/50, GE Healthcare) and size-exclusion chromatography (Superdex 200, GE Healthcare). The six-glutamate tagged tail was cleaved with the $3 \mathrm{C}$ protease (GE Healthcare). 


\section{Calcium flux experiments}

T cells $\left(0.5-1 \times 10^{6}\right)$ were loaded with $5 \mu \mathrm{M}$ Fura-2 (Invitrogen) in complete RPMI-1640 medium for $30 \mathrm{~min}$ at $25^{\circ} \mathrm{C}$ and then washed twice with $10 \mathrm{ml}$ imaging buffer $(1 \times \mathrm{HBSS}$, Gibco, supplemented with 2\% FCS, Sigma, $10 \mathrm{mM}$ HEPES pH 7.4, Gibco, $1 \mathrm{mM} \mathrm{MgCl} 2$ and $1 \mathrm{mM} \mathrm{CaCl}_{2}$ ). For imaging, cells were spotted on a supported lipid bilayer functionalized with MonoSAv (50 ng/well) linked to CD3-biotin antibodies (OKT-3, eBioscience) at $25{ }^{\circ} \mathrm{C}$. Image acquisition was performed with a DMI4000B microscope (Leica Microsystems) equipped with a 40x immersion objective (Leica HCX PL Apo 40×, NA 1.25) and an Andor iXon Ultra-8871 EM-CCD camera (Andor Technologies) controlled by the Leica Application Suite Advanced Fluorescence software (version AF6000LX). Imaging of Fura-2 (excitation, $340 \mathrm{~nm}$ and $380 \mathrm{~nm}$; emission, $510 \mathrm{~nm}$ ) was achieved through a fast external filter wheel equipped with excitation filers at $340 \mathrm{~nm}$ and $380 \mathrm{~nm}$ (Leica Fura EX) and a filter cube consisting of a dichroic beamsplitter and an emission band pass filter at $520 \mathrm{~nm}$ (Fura-2 Leica EM520/36, DC:409). DIC and Fura-2 images were collected at intervals of $1 \mathrm{~min}$ over $15 \mathrm{~min}$. Intracellular calcium dynamics were determined from the Fura-2 excitation ratio (excitation at $340 \mathrm{~nm} /$ excitation at $380 \mathrm{~nm}$ ) with the open source image analysis software package Fiji and Matlab.

Calcium flux measurement in shRNA cell lines was performed using Indo-1 Calcium Indicator (Life-Technologies). $24 \mathrm{~h}$ after doxycycline induction cells were labeled with Indo-1 Calcium Indicator stimulated with OKT3 (eBiosciences) and analyzed on a BD LSRFortessa. Data were analyzed using FlowJo Software.

\section{NK-cell experiments on patient cells and CRISPR edited NK-92 cell lines}

Conjugates of NK-92 CRISPR edited cells and K562 cells were formed for 60 min at $37{ }^{\circ} \mathrm{C}$ on silane coated slides (Electron Microscopy Services) and then permeabilized, fixed and stained for F-actin with phalloidin Alexa-Fluor568, anti-perforin Alexa-Fluor488 (clone G9, BioLegend) and anti-a-tubulin biotin (Life Technologies) followed by streptavidin AlexaFluor647 (Life Technologies). Conjugates were imaged as $z$ stacks of $0.2-\mu \mathrm{m}$ thickness to cover the entire volume of the immunological synapse, determined individually for each conjugate, on a Zeiss Axio-Observer Z1 equipped with a Yokogawa CSU10 spinning disc, Zeiss $63 \times 1.43$ NA objective, and Hamamatsu Orca-AG camera. Images were acquired and analyzed with Volocity software (PerkinElmer) as described68.

For measurement of F-actin mesh in patient cells, PBMC were activated for 25 min on \#1.5 coverslips coated with $5 \mu \mathrm{g} / \mathrm{ml}$ anti-CD18 (clone IB4) and anti-NKp30 (BioLegend) then fixed, permeabilized and stained with phalloidin Alexa-Fluor532 (Life Technologies) and anti-perforin Alexa-Fluor488 (clone $\delta G 9$, BioLegend). Slides were mounted with ProLong Gold (Life Technologies). Stimulation emission depletion (STED) images were acquired on a Leica SP8 confocal microscope with excitation by white light laser, STED depletion at 660 $\mathrm{nm}$ with time-gating, and emission detected by HyD (GaAs) detectors. Data was exported to Volocity software (PerkinElmer) for analysis following deconvolution with Huygens software (Scientific Volume Imaging). All data was graphed using Prism 6.0 (GraphPad). Statistical analysis was performed using the Student's two-tailed unpaired $t$ test. $P<0.05$ was considered significant. 


\section{Analysis of RhoA activation by immunofluorescence}

Untransformed CD8 ${ }^{+} \mathrm{T}$ cells were expanded with a feeder mixture and a supplement of IL-2 and IL-15, as described above. Cells $\left(2 \times 10^{5}\right)$ were treated with lenalidomide $(1 \mu \mathrm{M})$ or $\operatorname{DMSO}(1: 1,000)$ in complete medium for $16 \mathrm{~h}$. Half of the cells were subsequently stimulated with CXCL12 $(100 \mathrm{ng} / \mathrm{ml})$ for $5 \mathrm{~min}$. Cells $\left(10^{5}\right.$ per condition) were then deposited onto poly-L-lysine-coated coverslips. Following a sedimentation of $5 \mathrm{~min}$ at $37^{\circ} \mathrm{C}$, cells were spun down for $2 \mathrm{~min}$ at $350 \mathrm{rpm}$. Cells were fixed with ice-cold $10 \%$ $\mathrm{TCA} / 30 \mathrm{mM}$ glycine onto coverslips as described69. Following incubation on ice for 15 min, coverslips were washed three times with PBS/glycine. Cells were permeabilized with $0.2 \%$ Triton X-100 in PBS/glycine, washed and blocked for 30 min with 3\% BSA, $0.01 \%$ Triton X-100 in PBS/glycine. Cells were stained with a rabbit mAb recognizing total RhoA (catalog number: 67B9, Cell Signaling) or active RhoA-GTP (catalog number: 26904, NewEast Biosciences) in a 1:50 dilution in 0.01\% Triton X-100 in PBS/glycine and incubated overnight at $4{ }^{\circ} \mathrm{C}$. Cells were incubated with anti-rabbit Alexa-Fluor555 or antimouse Alexa-Fluor 488 secondary Abs at 1/400 dilution. Following nuclear staining with DAPI, slides were mounted with Prolong Gold antifade mounting medium (Life Technologies). Randomly selected fields were examined with a Leica DMI 6000B fluorescence microscope equipped with a $40 \times$ objective. The mean intensity of total RhoA and RhoA-GTP was calculated from 8-bit images in 50 cells per condition using cell masks created with ImageJ software.

\section{SiR-tubulin staining and live convergence imaging}

For imaging NK cells on activated glass surface, $3 \times 10^{5} \mathrm{NK}$ cells were incubated with 500 $\mathrm{nm}$ of the live cell fluorogenic microtubule labeling probe SiR-tubulin (Spirochrome) and 5 $\mu \mathrm{m}$ Verapamil for $2 \mathrm{~h}$ at $37^{\circ} \mathrm{C}$. For imaging lytic granules, cells were incubated with $1 \mu \mathrm{M}$ LysoTracker Red DND-99 (Thermo Fisher Scientific) for $30 \mathrm{~min}$ at $37^{\circ} \mathrm{C}$, washed once, and resuspended in dye-free R10 (RPMI 1640 (Gibco), 10\% FBS (Atlanta Biologicals), 2 mM L-glutamine (Gibco), $1 \mathrm{mM}$ sodium pyruvate (CellGro), $10 \mathrm{mM}$ HEPES (Gibco), $100 \mu \mathrm{M}$ MEM nonessential amino acids (Gibco), and $100 \mathrm{U} / \mathrm{ml}$ penicillin and streptomycin), supplemented with $5 \mu \mathrm{m}$ Verapamil. $\Delta \mathrm{T}$ dishes (Bioptechs) were coated with $5 \mu \mathrm{g} / \mathrm{ml}$ antiNKp30 (BioLegend) and $5 \mu \mathrm{g} / \mathrm{ml}$ anti-CD18 (Clone IB4) for $1 \mathrm{~h}$ at $37^{\circ} \mathrm{C}$, washed with PBS, and pre-warmed before imaging with $300 \mu \mathrm{l}$ dye-free R10.

For imaging of NK cells with K562 target cells, $10^{5}$ LysoTracker Red-loaded NK cells (effectors) were stained with $500 \mathrm{~nm} \mathrm{SiR-tubulin}$ and $5 \mu \mathrm{m}$ Verapamil for $2 \mathrm{~h}$ at $37^{\circ} \mathrm{C}$, washed once, resuspended in dye-free $\mathrm{R} 10$, and then mixed at a 1:2 ratio with target cells that had been pre-incubated for 5 min with $2.5 \mu \mathrm{M}$ CellTrace CFSE (Thermo Fisher Scientific). Conjugates were incubated in $1 \mathrm{ml}$ microcentrifuge tubes in the presence of $5 \mu \mathrm{m}$ Verapamil for $30 \mathrm{~min}$ at $37^{\circ} \mathrm{C}$ and plated in Lab-Tek \#1.0 Borosilicate chamber slides (Nunc) pre-coated with $5 \mu \mathrm{g} / \mathrm{ml}$ anti-CD58 (BD Pharmingen) for $30 \mathrm{~min}$ at $37^{\circ}$ and washed with PBS. Target cells were allowed to adhere to glass for $15 \mathrm{~min}$ and conjugates were imaged at 30s per frame for 30-45 min on a Leica SP8 laser scanning confocal microscope with $100 \times$ objective. Excitation was provided by a tunable white light laser at 488, 561 and $647 \mathrm{~nm}$. 
For evaluation of lytic granule convergence, raw images were analyzed in Volocity (PerkinElmer) and mean granule distance (MGD) to the MTOC was calculated as described previously32. Number of replicates performed $=3$ for both types of experiments. Graphs were plotted in Prism (GraphPad) showing mean values with s.e.m. Statistical test used is unpaired $t$ test with Welch's correction.

\section{Supplementary Material}

Refer to Web version on PubMed Central for supplementary material.

\section{Acknowledgments}

We thank the patient and his family for participating in this study; B. Fleckenstein and M. Schmidt for generating and providing patient-derived T cell lines; and G. Superti-Furga, J. Bigenzahn for providing the inducible protein expression system used for Jurkat T cells and together with N. Serwas, C.D. Conde, A. Kalinichenko, K. Ackerman and R. Martins for critically reviewing the manuscript and providing comments. The research leading to these results was funded by the European Research Council under the European Union's Seventh Framework Programme (FP7/2007-2013) / ERC grant agreement 310857 (K.B.), the Vienna Science and Technology Fund (WWTF) through project LS14-031 (J.B.H. and K.B.), an unrestricted research grant from Celgene Austria (U.J.), the National Institutes of Health (R01AI067946 to J.S.O.), Boehringer Ingelheim Fonds (R.P.), the Austrian Science Fund (FWF): Project M1809-B19 (K.L.W.), and the French Agence Nationale de la Recherche (ANR-13BSV1-0031 to L.D.).

\section{References}

1. Roose J, Weiss A. T cells: getting a GRP on Ras. Nat Immunol. 2000; 1:275-276. [PubMed: 11017094]

2. Stone JC. Regulation and function of the RasGRP family of Ras activators in blood cells. Genes Cancer. 2011; 2:320-334. [PubMed: 21779502]

3. Downward J, Graves JD, Warne PH, Rayter S, Cantrell DA. Stimulation of p21ras upon T-cell activation. Nature. 1990; 346:719-723. [PubMed: 2201921]

4. Kremer KN, Kumar A, Hedin KE. G alpha 2 and ZAP-70 mediate RasGRP1 membrane localization and activation of SDF-1-induced T cell functions. J Immunol. 2011; 187:3177-3185. [PubMed: 21856938]

5. Dower NA, et al. RasGRP is essential for mouse thymocyte differentiation and TCR signaling. Nat Immunol. 2000; 1:317-321. [PubMed: 11017103]

6. Khanna R, Burrows SR. Human immunology: a case for the ascent of non-furry immunology. Immunol Cell Biol. 2011; 89:330-331. [PubMed: 21412238]

7. Mestas J, Hughes CC. Of mice and not men: differences between mouse and human immunology. J Immunol. 2004; 172:2731-2738. [PubMed: 14978070]

8. Waterston $\mathrm{RH}$, et al. Initial sequencing and comparative analysis of the mouse genome. Nature. 2002; 420:520-562. [PubMed: 12466850]

9. Notarangelo LD. Functional T cell immunodeficiencies (with T cells present). Annu Rev Immunol. 2013; 31:195-225. [PubMed: 23298211]

10. Notarangelo LD. Partial defects of T-cell development associated with poor T-cell function. J Allergy Clin Immunol. 2013; 131:1297-1305. [PubMed: 23465662]

11. Picard C, et al. Primary immunodeficiency diseases: an update on the classification from the International Union of Immunological Societies Expert Committee for Primary Immunodeficiency 2015. J Clin Immunol. 2015; 35:696-726. [PubMed: 26482257]

12. Bousfiha A, et al. The 2015 IUIS phenotypic classification for primary immunodeficiencies. J Clin Immunol. 2015; 35:727-738. [PubMed: 26445875]

13. Espinós $\mathrm{C}$, et al. Mutations in the urocanase gene UROC1 are associated with urocanic aciduria. $\mathrm{J}$ Med Genet. 2009; 46:407-411. [PubMed: 19304569] 
14. Chen Y, et al. Differential requirement of RasGRP1 for $\gamma \delta \mathrm{T}$ cell development and activation. $\mathrm{J}$ Immunol. 2012; 189:61-71. [PubMed: 22623331]

15. Warnecke N, et al. TCR-mediated Erk activation does not depend on Sos and Grb2 in peripheral human T cells. EMBO Rep. 2012; 13:386-391. [PubMed: 22344067]

16. Jun JE, Rubio I, Roose JP. Regulation of ras exchange factors and cellular localization of ras activation by lipid messengers in T cells. Front Immunol. 2013; 4:239. [PubMed: 24027568]

17. Depeille P, et al. RasGRP1 opposes proliferative EGFR-SOS1-Ras signals and restricts intestinal epithelial cell growth. Nat Cell Biol. 2015; 17:804-815. [PubMed: 26005835]

18. Shen S, et al. Critical roles of RasGRP1 for invariant NKT cell development. J Immunol. 2011; 187:4467-4473. [PubMed: 21957144]

19. Montoya CJ, et al. Characterization of human invariant natural killer T subsets in health and disease using a novel invariant natural killer T cell-clonotypic monoclonal antibody, 6B11. Immunology. 2007; 122:1-14. [PubMed: 17662044]

20. Priatel JJ, et al. Chronic immunodeficiency in mice lacking RasGRP1 results in CD4 T cell immune activation and exhaustion. J Immunol. 2007; 179:2143-2152. [PubMed: 17675473]

21. Ma CS, Deenick EK. Human T follicular helper (Tfh) cells and disease. Immunol Cell Biol. 2014; 92:64-71. [PubMed: 24145858]

22. Bartlett A, Buhlmann JE, Stone J, Lim B, Barrington RA. Multiple checkpoint breach of B cell tolerance in Rasgrp1-deficient mice. J Immunol. 2013; 191:3605-3613. [PubMed: 23997211]

23. Coughlin JJ, Stang SL, Dower NA, Stone JC. RasGRP1 and RasGRP3 regulate B cell proliferation by facilitating B cell receptor-Ras signaling. J Immunol. 2005; 175:7179-7184. [PubMed: 16301621]

24. Sun C, et al. High-density genotyping of immune-related loci identifies new SLE risk variants in individuals with Asian ancestry. Nat Genet. 2016; 48:323-330. [PubMed: 26808113]

25. Tangye SG, Ferguson A, Avery DT, Ma CS, Hodgkin PD. Isotype switching by human B cells is division-associated and regulated by cytokines. J Immunol. 2002; 169:4298-4306. [PubMed: 12370361]

26. Thien M, et al. Excess BAFF rescues self-reactive B cells from peripheral deletion and allows them to enter forbidden follicular and marginal zone niches. Immunity. 2004; 20:785-798. [PubMed: 15189742]

27. Perussia B, Chen Y, Loza MJ. Peripheral NK cell phenotypes: multiple changing of faces of an adapting, developing cell. Mol Immunol. 2005; 42:385-395. [PubMed: 15607789]

28. Navarro MN, Cantrell DA. Serine-threonine kinases in TCR signaling. Nat Immunol. 2014; 15:808-814. [PubMed: 25137455]

29. Okamura SM, Oki-Idouchi CE, Lorenzo PS. The exchange factor and diacylglycerol receptor RasGRP3 interacts with dynein light chain 1 through its C-terminal domain. J Biol Chem. 2006; 281:36132-36139. [PubMed: 17012239]

30. Rodríguez-Crespo I, et al. Identification of novel cellular proteins that bind to the LC8 dynein light chain using a pepscan technique. FEBS Lett. 2001; 503:135-141. [PubMed: 11513870]

31. Huse M. Microtubule-organizing center polarity and the immunological synapse: protein kinase C and beyond. Front Immunol. 2012; 3:235. [PubMed: 23060874]

32. Mentlik AN, Sanborn KB, Holzbaur EL, Orange JS. Rapid lytic granule convergence to the MTOC in natural killer cells is dependent on dynein but not cytolytic commitment. Mol Biol Cell. 2010; 21:2241-2256. [PubMed: 20444980]

33. Roose JP, Mollenauer M, Gupta VA, Stone J, Weiss A. A diacylglycerol-protein kinase CRasGRP1 pathway directs Ras activation upon antigen receptor stimulation of T cells. Mol Cell Biol. 2005; 25:4426-4441. [PubMed: 15899849]

34. Li R, Gundersen GG. Beyond polymer polarity: how the cytoskeleton builds a polarized cell. Nat Rev Mol Cell Biol. 2008; 9:860-873. [PubMed: 18946475]

35. Liu Y, Zhu M, Nishida K, Hirano T, Zhang W. An essential role for RasGRP1 in mast cell function and IgE-mediated allergic response. J Exp Med. 2007; 204:93-103. [PubMed: 17190838] 
36. Ramsay AG, et al. Chronic lymphocytic leukemia cells induce defective LFA-1-directed T-cell motility by altering Rho GTPase signaling that is reversible with lenalidomide. Blood. 2013; 121:2704-2714. [PubMed: 23325833]

37. Richardson PG, et al. Lenalidomide, bortezomib, and dexamethasone combination therapy in patients with newly diagnosed multiple myeloma. Blood. 2010; 116:679-686. [PubMed: 20385792]

38. Krönke J, et al. Lenalidomide causes selective degradation of IKZF1 and IKZF3 in multiple myeloma cells. Science. 2014; 343:301-305. [PubMed: 24292625]

39. Gandhi AK, et al. Immunomodulatory agents lenalidomide and pomalidomide costimulate T cells by inducing degradation of $\mathrm{T}$ cell repressors Ikaros and Aiolos via modulation of the E3 ubiquitin ligase complex CRL4(CRBN.). Br J Haematol. 2014; 164:811-821. [PubMed: 24328678]

40. Casanova JL, Conley ME, Seligman SJ, Abel L, Notarangelo LD. Guidelines for genetic studies in single patients: lessons from primary immunodeficiencies. J Exp Med. 2014; 211:2137-2149. [PubMed: 25311508]

41. Fuller DM, et al. Regulation of RasGRP1 function in T cell development and activation by its unique tail domain. PLoS One. 2012; $7:$ e38796. [PubMed: 22719950]

42. Vivier E, Tomasello E, Baratin M, Walzer T, Ugolini S. Functions of natural killer cells. Nat Immunol. 2008; 9:503-510. [PubMed: 18425107]

43. Thrasher AJ, Burns SO. WASP: a key immunological multitasker. Nat Rev Immunol. 2010; 10:182-192. [PubMed: 20182458]

44. Lanzi G, et al. A novel primary human immunodeficiency due to deficiency in the WASPinteracting protein WIP. J Exp Med. 2012; 209:29-34. [PubMed: 22231303]

45. McGhee SA, Chatila TA. DOCK8 immune deficiency as a model for primary cytoskeletal dysfunction. Dis Markers. 2010; 29:151-156. [PubMed: 21178274]

46. Liu X, Kapoor TM, Chen JK, Huse M. Diacylglycerol promotes centrosome polarization in T cells via reciprocal localization of dynein and myosin II. Proc Natl Acad Sci USA. 2013; 110:1197611981. [PubMed: 23818610]

47. Schroeder CM, Ostrem JM, Hertz NT, Vale RD. A Ras-like domain in the light intermediate chain bridges the dynein motor to a cargo-binding region. eLife. 2014; 3:e03351. [PubMed: 25272277]

48. Jayappa KD, et al. Human immunodeficiency virus type 1 employs the cellular dynein light chain 1 protein for reverse transcription through interaction with its integrase protein. J Virol. 2015; 89:3497-3511. [PubMed: 25568209]

49. Zenz T. Exhausting T cells in CLL. Blood. 2013; 121:1485-1486. [PubMed: 23449612]

50. Salzer E, et al. Combined immunodeficiency with life-threatening EBV-associated lymphoproliferative disorder in patients lacking functional CD27. Haematologica. 2013; 98:473478. [PubMed: 22801960]

51. Willmann KL, et al. Biallelic loss-of-function mutation in NIK causes a primary immunodeficiency with multifaceted aberrant lymphoid immunity. Nat Commun. 2014; 5:5360. [PubMed: 25406581]

52. Kircher M, et al. A general framework for estimating the relative pathogenicity of human genetic variants. Nat Genet. 2014; 46:310-315. [PubMed: 24487276]

53. Dupré L, et al. Efficacy of gene therapy for Wiskott-Aldrich syndrome using a WAS promoter/ cDNA-containing lentiviral vector and nonlethal irradiation. Hum Gene Ther. 2006; 17:303-313. [PubMed: 16544979]

54. Dupré L, et al. Lentiviral vector-mediated gene transfer in T cells from Wiskott-Aldrich syndrome patients leads to functional correction. Mol Ther. 2004; 10:903-915. [PubMed: 15509508]

55. Pichlmair A, et al. Viral immune modulators perturb the human molecular network by common and unique strategies. Nature. 2012; 487:486-490. [PubMed: 22810585]

56. Glatter T, Wepf A, Aebersold R, Gstaiger M. An integrated workflow for charting the human interaction proteome: insights into the PP2A system. Mol Syst Biol. 2009; 5:237. [PubMed: 19156129]

57. Dow LE, et al. A pipeline for the generation of shRNA transgenic mice. Nat Protoc. 2012; 7:374393. [PubMed: 22301776] 
58. Zuber J, et al. An integrated approach to dissecting oncogene addiction implicates a Mybcoordinated self-renewal program as essential for leukemia maintenance. Genes Dev. 2011; 25:1628-1640. [PubMed: 21828272]

59. Ran FA, et al. Genome engineering using the CRISPR-Cas9 system. Nat Protoc. 2013; 8:22812308. [PubMed: 24157548]

60. Sanjana NE, Shalem O, Zhang F. Improved vectors and genome-wide libraries for CRISPR screening. Nat Methods. 2014; 11:783-784. [PubMed: 25075903]

61. Brinkman EK, Chen T, Amendola M, van Steensel B. Easy quantitative assessment of genome editing by sequence trace decomposition. Nucleic Acids Res. 2014; 42:e168. [PubMed: 25300484]

62. Boztug K, et al. JAGN1 deficiency causes aberrant myeloid cell homeostasis and congenital neutropenia. Nat Genet. 2014; 46:1021-1027. [PubMed: 25129144]

63. Mellacheruvu D, et al. The CRAPome: a contaminant repository for affinity purification-mass spectrometry data. Nat Methods. 2013; 10:730-736. [PubMed: 23921808]

64. Vasconcelos Z, et al. Individual human cytotoxic T lymphocytes exhibit intraclonal heterogeneity during sustained killing. Cell Rep. 2015; 11:1474-1485. [PubMed: 26027932]

65. Huppa JB, et al. TCR-peptide-MHC interactions in situ show accelerated kinetics and increased affinity. Nature. 2010; 463:963-967. [PubMed: 20164930]

66. Fairhead M, Krndija D, Lowe ED, Howarth M. Plug-and-play pairing via defined divalent streptavidins. J Mol Biol. 2014; 426:199-214. [PubMed: 24056174]

67. Howarth M, et al. A monovalent streptavidin with a single femtomolar biotin binding site. Nat Methods. 2006; 3:267-273. [PubMed: 16554831]

68. Banerjee PP, Orange JS. Quantitative measurement of F-actin accumulation at the NK cell immunological synapse. J Immunol Methods. 2010; 355:1-13. [PubMed: 20171970]

69. Trifari $\mathrm{S}$, et al. Defective $\mathrm{T}_{\mathrm{h}} 1$ cytokine gene transcription in $\mathrm{CD}^{+}$and $\mathrm{CD} 8^{+} \mathrm{T}$ cells from WiskottAldrich syndrome patients. J Immunol. 2006; 177:7451-7461. [PubMed: 17082665] 

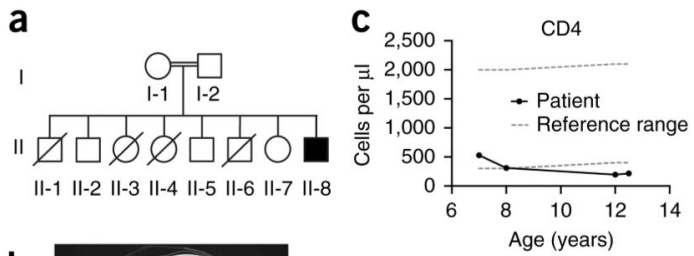

b
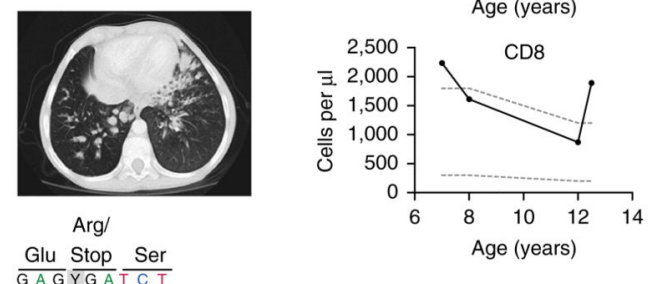
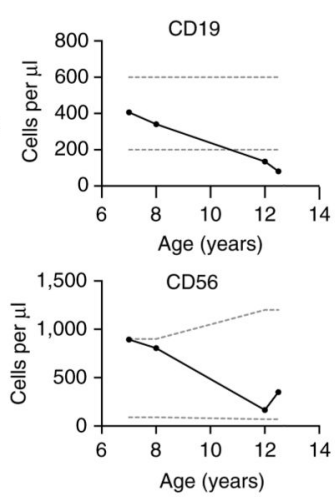

f

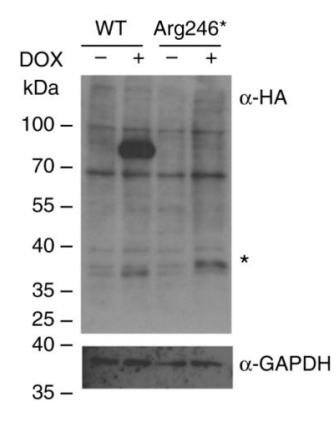

g

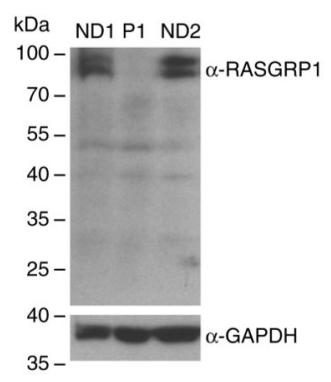

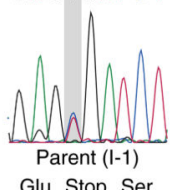
Glu Stop Se $\frac{G A G}{T A G A} \frac{S T}{T C T}$
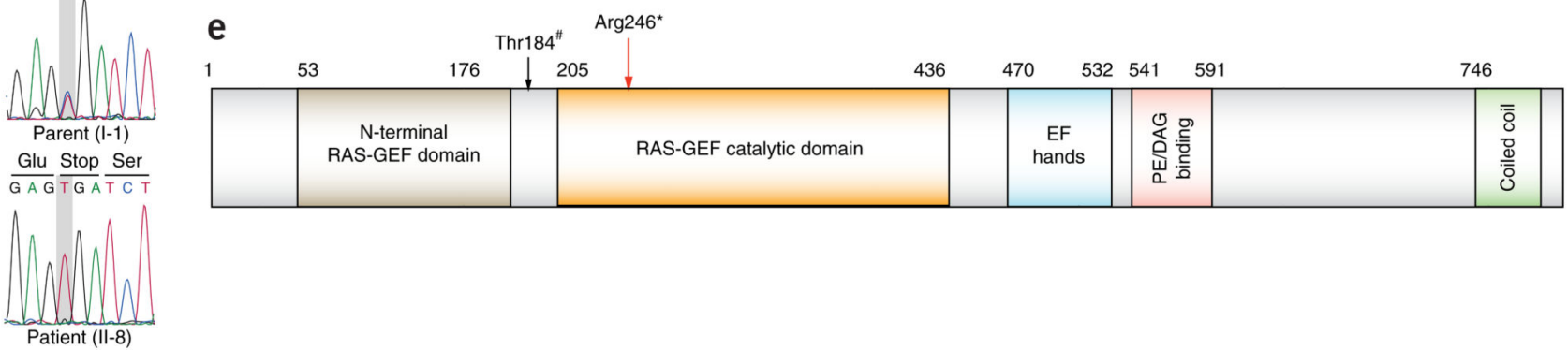

Figure 1. Identification of human RASGRP1 deficiency.

(a) Pedigree of the index family: double lines indicate consanguinity; filled black indicates the index patient; diagonal lines indicate deceased siblings. (b) Computed tomography scan of the index patient showing bronchiectatic segments, centrilobular nodular opacities, and paratracheal, subcarinal and bilateral hilar lymphadenopathy. (c) Longitudinal peripheral blood lymphocyte counts (exact measurements, Supplementary Table 1); gray dotted lines represent reference values. (d) Capillary sequencing confirmation of the stop-gain mutation in RASGRP1 (c. C726T, p. Arg246*). (e) RASGRP1 protein domains: red arrow indicates position of the stop-gain mutation; black arrow indicates the Thr184 PKC-phosphorylation site (Thr184\#). (f) Cropped immunoblot analysis of wild-type (WT) and mutant (Arg246*) RASGRP1 tagged at the amino terminus with Strep-HA-in doxycyclin-inducible HEK293T cells. *, expected size of the truncated protein. (g) Cropped immunoblot analysis of fulllength RASGRP1 in EBV-immortalized B cells from the patient (P1) and two normal donors (ND). Data are representative of four (f) or two (g) independent experiments. 

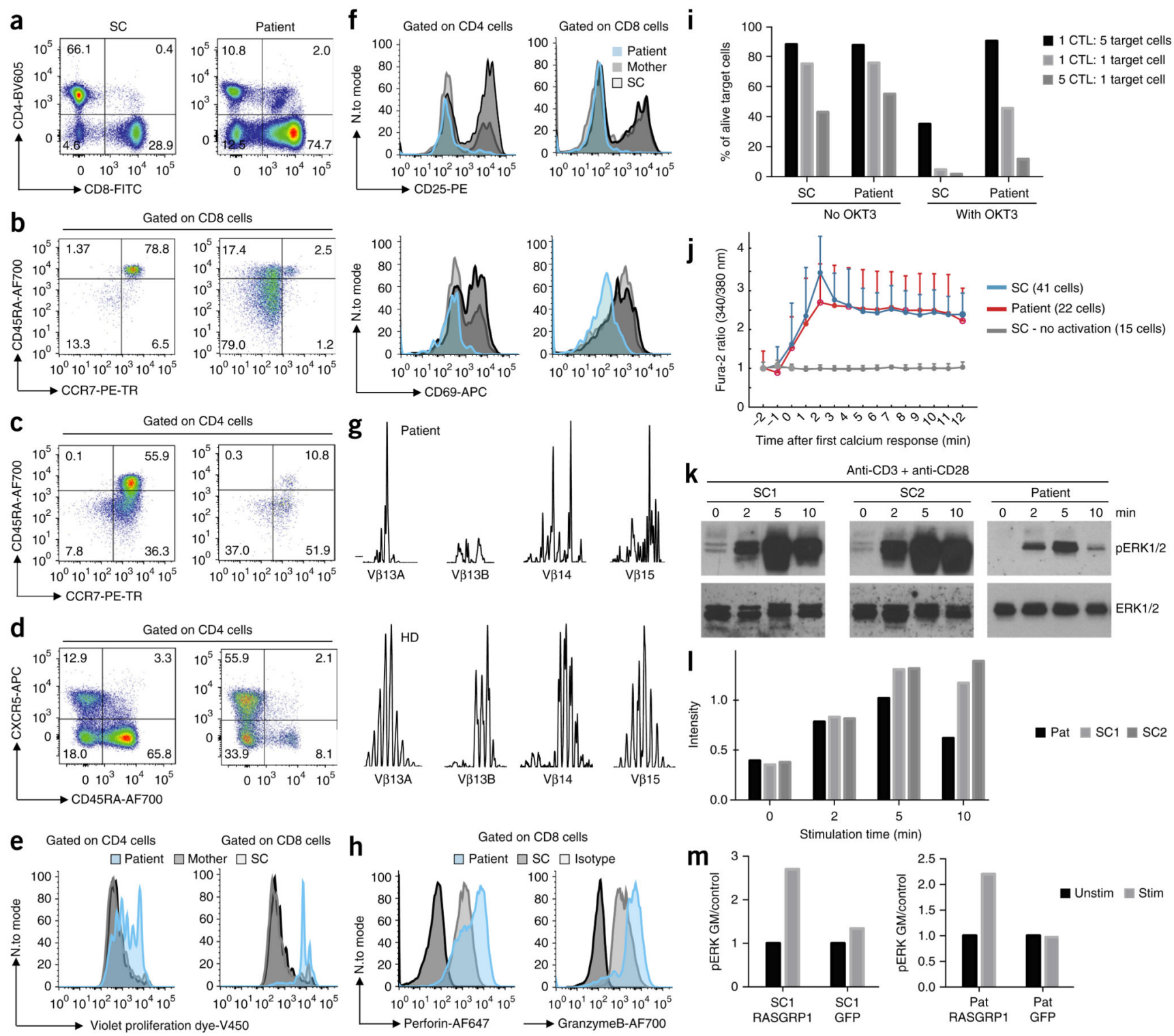

Figure 2. RASGRP1deficiency causes defective TCR signaling and an aberrant immunophenotype.

(a-d) T cell immunophenotyping displaying relative proportions of $\mathrm{CD}^{+}$cells and $\mathrm{CD} 8^{+}$ cells amongst $\mathrm{CD}^{+}$cells in lymphocyte gate $(\mathbf{a})$, proportions of naive $\left(\mathrm{CD}^{2} 5 \mathrm{RA}^{+} \mathrm{CCR} 7^{+}\right)$, central memory $\left(\mathrm{CD} 45 \mathrm{RA}^{-} \mathrm{CCR} 7^{+}\right) \mathrm{T}$ cells, effector memory $\left(\mathrm{CD} 45 \mathrm{RA}^{-} \mathrm{CCR} 7^{-}\right) \mathrm{T}$ cells and exhausted effector memory $\left(\mathrm{CD}^{2} 5 \mathrm{RA}^{+} \mathrm{CCR}^{-}\right) \mathrm{T}$ cells among $\mathrm{CD} 8^{+} \mathrm{T}$ cells $(\mathbf{b})$ and $\mathrm{CD}^{+}{ }^{+} \mathrm{T}$ cells (c), and the relative abundance of $\mathrm{CXCR}^{+} \mathrm{CD} 45 \mathrm{RA}^{-}$cells and naive

$\left(\mathrm{CXCR}^{-}{ }^{-} \mathrm{CD} 45 \mathrm{RA}^{+}\right)$cells among $\mathrm{CD} 4^{+}$cells $(\mathbf{d})$. Full gating strategy, Supplementary

Figure 3. (e) Proliferation of $\mathrm{CD}^{+}$and $\mathrm{CD} 8^{+} \mathrm{T}$ cells at day 4 after stimulation with antiCD3 and anti-CD28. (f) Expression of CD25 and CD69 $24 \mathrm{~h}$ after stimulation with anti-CD3 and anti-CD28. (g) TCR V $\mathrm{\beta}_{\beta}$ spectra-typing of the patient's peripheral blood T cells. (h) Expression of perforin and granzyme B on the patient's $\mathrm{CD} 8^{+} \mathrm{T}$ cells. (i) Killing of target cells by $\mathrm{CD} 8^{+} \mathrm{T}$ cells with (right) or without (left) OKT3. CTL, cytotoxic T lymphocytes. (j) 
Microscopy of intracellular $\mathrm{Ca}^{2+}$ flux in immortalized $\mathrm{T}$ cell lines following stimulation with anti-CD3, assessed by detection of the Fura-2 excitation ratio. (k) Cropped immunoblot analysis of total and phosphorylated (p-) ERK in primary T cells after stimulation with antiCD3 and anti-CD28. (l) Quantification of the results in k. (m) Geometric mean (GM) of phosphorylated ERK in the patient's $\mathrm{CD} 8^{+} \mathrm{T}$ cells and shipment control $\mathrm{CD} 8^{+} \mathrm{T}$ cells transfected to express a vector encoding wild-type RASGRP1 or a vector encoding green fluorescent protein (GFP) as control. Data are representative of eight (a), four (b,c), three $(\mathbf{e}, \mathbf{f}, \mathbf{h}, \mathbf{i}, \mathbf{m})$ or two $(\mathbf{d}, \mathbf{g}, \mathbf{j}, \mathbf{k})$ independent experiments. 
a
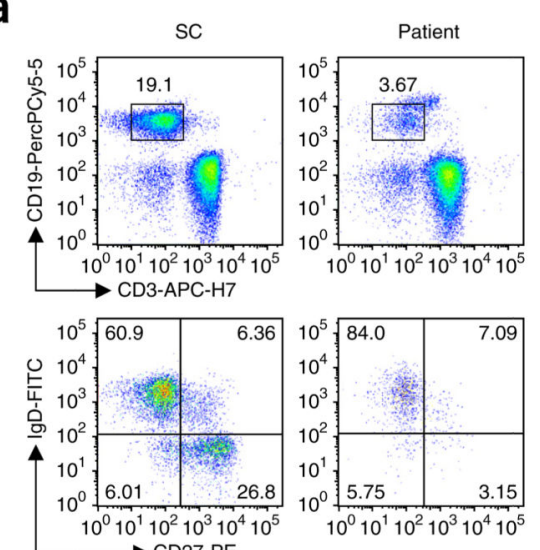

$\rightarrow \mathrm{CD} 27-\mathrm{PE}$

\section{b}
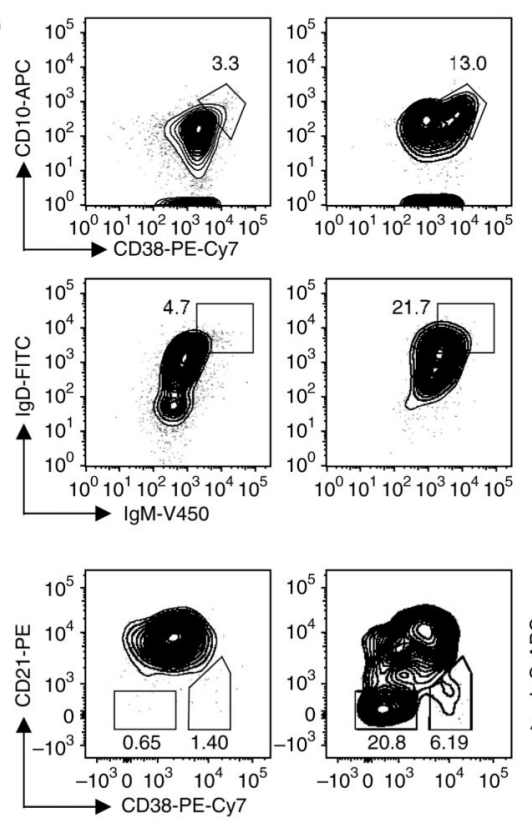
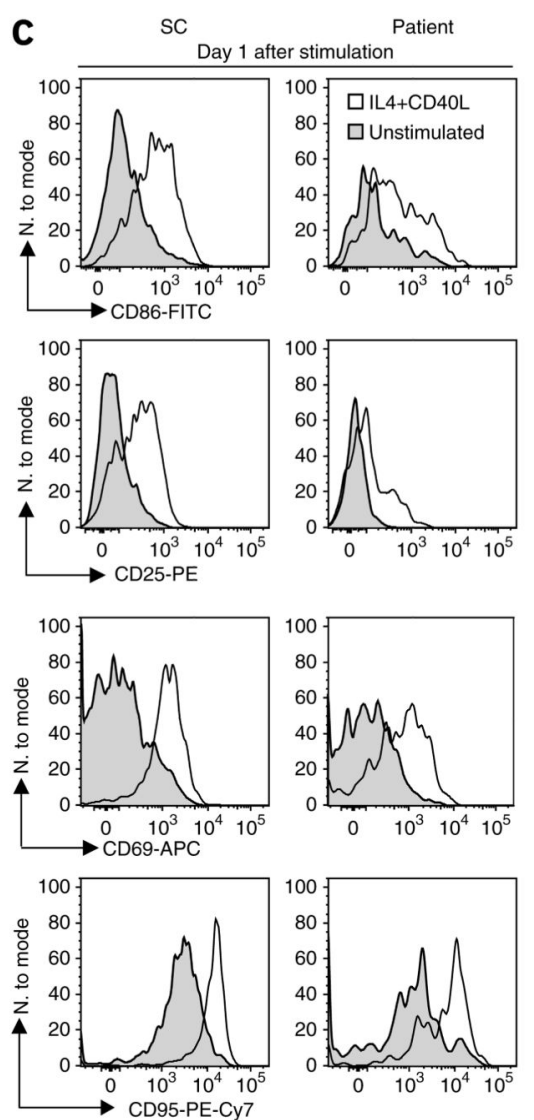

d

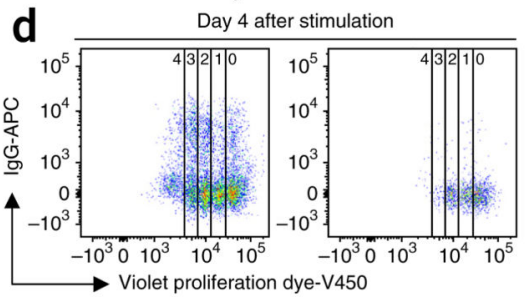

e
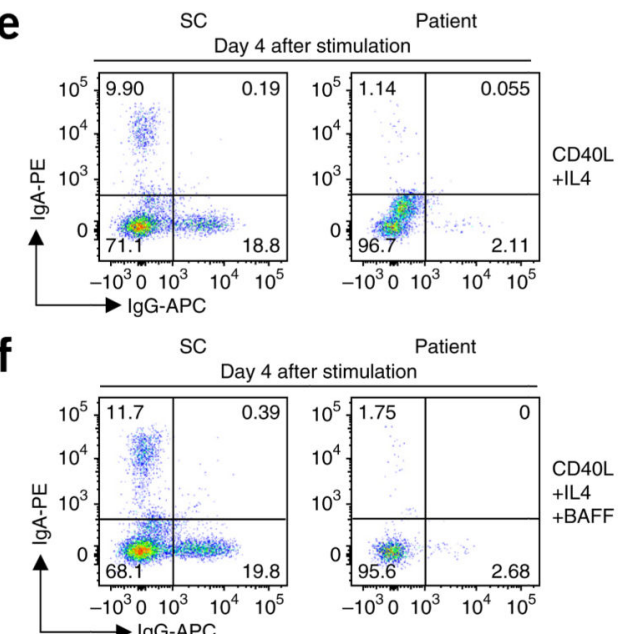

g

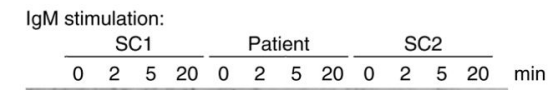

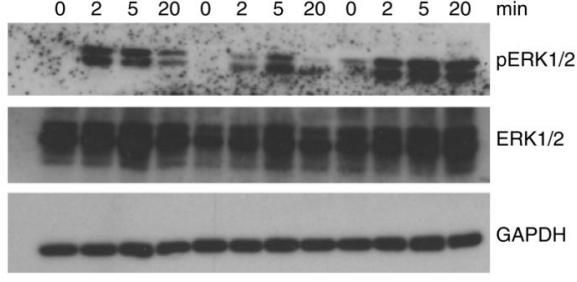

$\mathbf{h}$

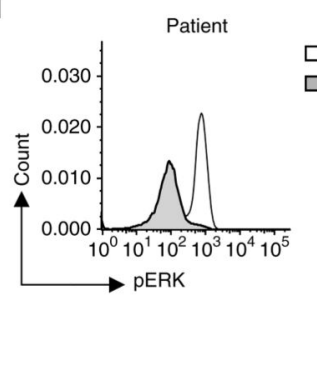

口RRRL RASGRP1_stim $\square$ pRRL GFP_stim

Figure 3. RASGRP1 deficiency results in a $B$ cell proliferation and activation defect.

(a) Showing relative proportion of naive $\left(\mathrm{IgD}^{+} \mathrm{CD} 27^{-}\right) \mathrm{B}$ cells, memory non-switched ( $\mathrm{IgD}$ $\left.{ }^{+} \mathrm{CD} 27^{+}\right) \mathrm{B}$ cells and memory-switched $\left(\mathrm{IgD}^{-} \mathrm{CD} 27^{+}\right) \mathrm{B}$ cells. Full gating strategy,

Supplementary Figure 3. (b) Flow cytometry of gated CD19+ B cells showing transitional $\mathrm{T} 1\left(\mathrm{CD} 10^{+} \mathrm{CD} 38^{+}\right) \mathrm{B}$ cells, transitional $\left(\mathrm{IgD}^{+} \mathrm{IgM}^{+}\right) \mathrm{B}$ cells and activated $\left(\mathrm{CD}^{2} 1^{-} \mathrm{CD} 38^{\mathrm{lo}}\right) \mathrm{B}$ cells. (c) Flow cytometric expression of CD86, CD95, CD25 and CD69 of CD19+ cells $1 \mathrm{~d}$ after stimulation with anti-CD40L and IL-4. (d) Proliferating B cells at day 4 after stimulation as in c. (e) $\operatorname{IgA}^{+}$and $\mathrm{IgG}^{+}$switched $\mathrm{B}$ cells at day 4 stimulation. (f) $\operatorname{IgA}^{+}$and $\mathrm{IgG}^{+}$switched B cells at day 4 stimulation as in $\mathbf{c}$ with (bottom) or without (top) the addition of BAFF. (g) Cropped immunoblot analysis of total and phosphorylated ERK in EBVtransformed B cells from the patient, assessed after stimulation with $\operatorname{IgM}$. (h) Phosphorylated ERK after gene transfer using a lentiviral backbone (pRRL) with sequence encoding wild-type RASGRP1 or GFP in EBV-transformed B cells from the patient, after 
stimulation with IgM. Data are representative of four $(\mathbf{a}, \mathbf{b})$, two $(\mathbf{c}, \mathbf{d}, \mathbf{g}, \mathbf{h})$ or one $(\mathbf{e}, \mathbf{f})$ independent experiment(s). 
a
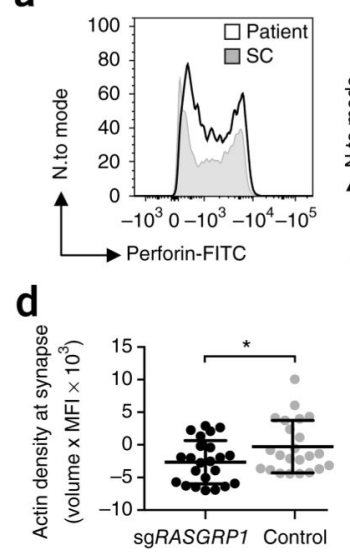

g

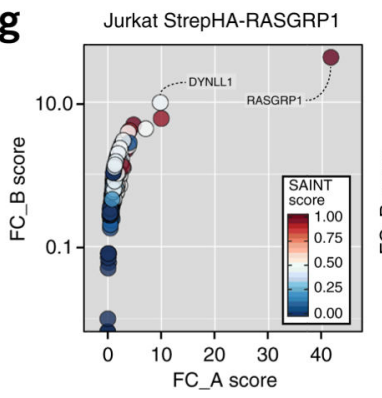

h

RASGRP3_human Rasgrp3 mouse Rasgrp3_rat Rasgrp3_chicken RASGRP1_human Rasgrp1_mouse Rasgrp1_rat
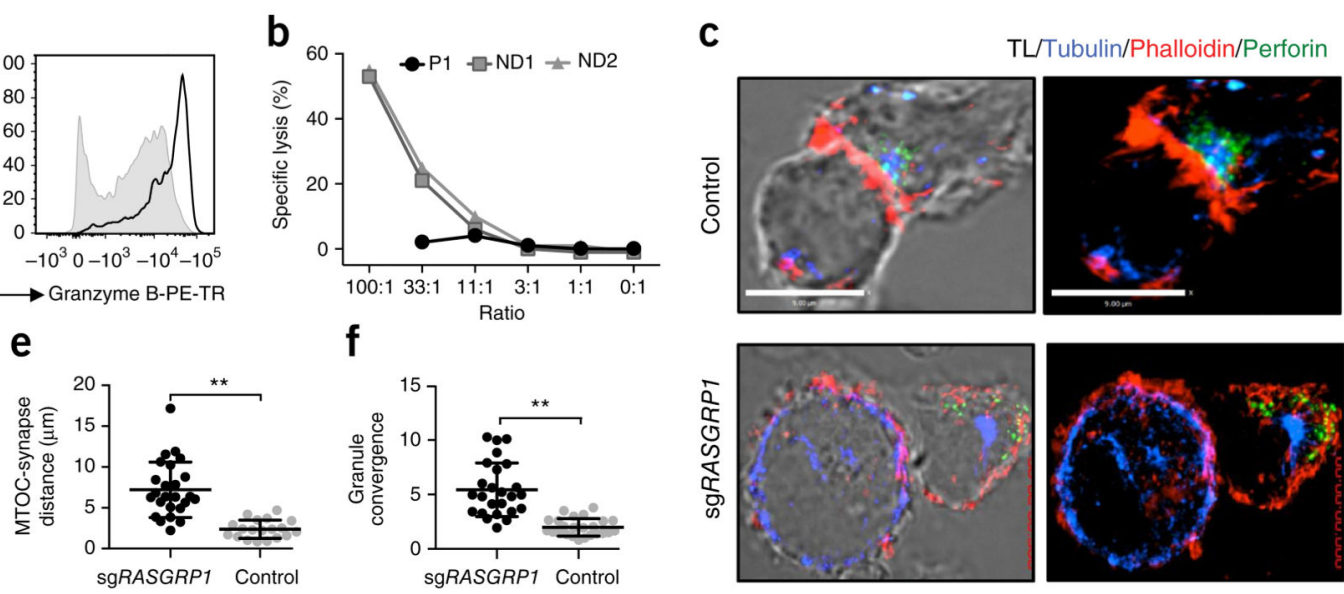

f
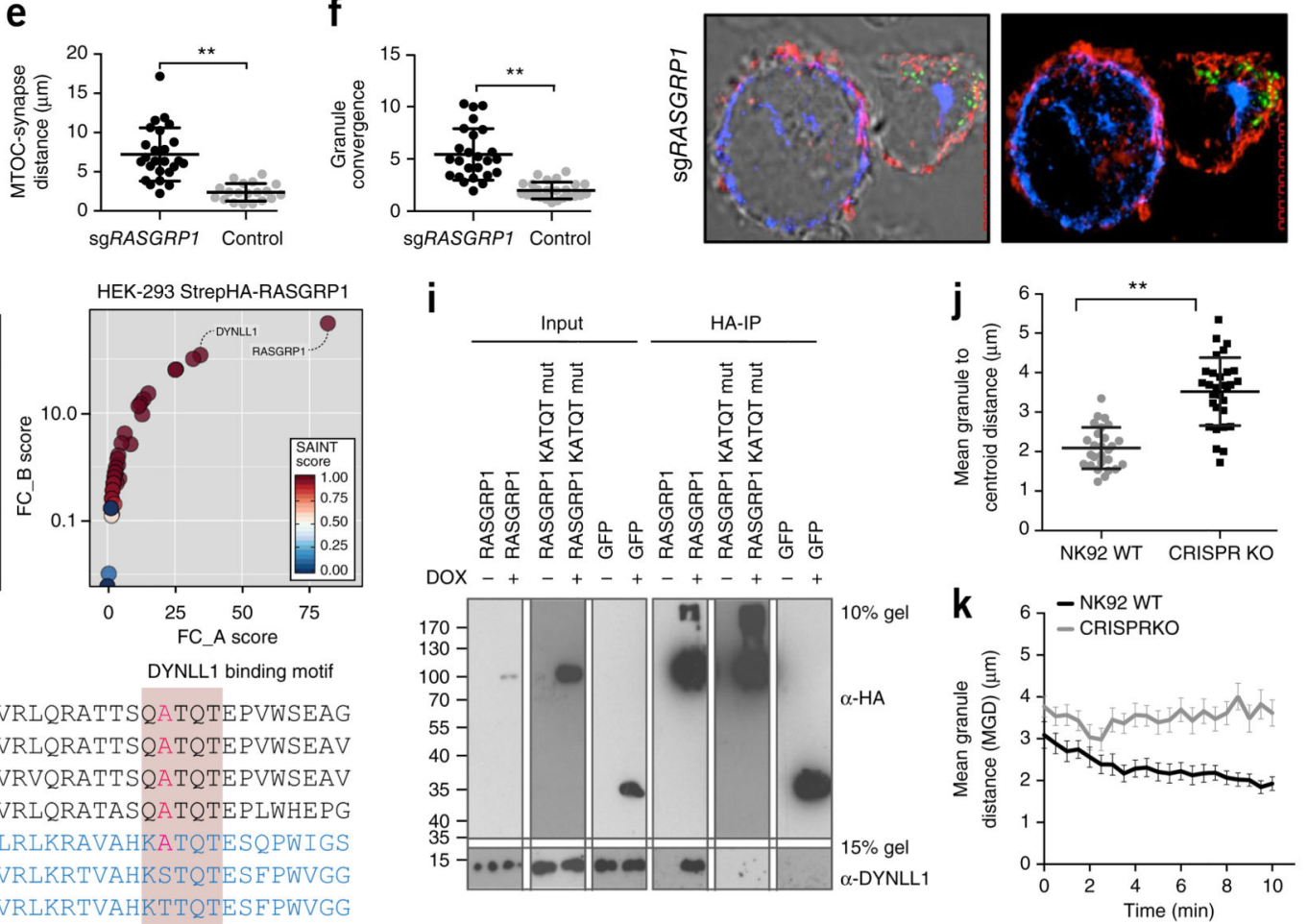

Figure 4. Aberrant cytoskeletal dynamics in NK cells.

(a) Flow cytometry analyzing the intracellular accumulation of perforin and granzyme B in NK cells from the patient and control donors. Full gating strategy, Supplementary Figure 4.

(b) Chromium $\left({ }^{51} \mathrm{Cr}\right)$-release assay of NK cell cytotoxicity. E/T, effector cell/target cell. (c) Confocal microscopy of a fixed RASGRP1 wild-type NK-92 control cell (top) and an NK-92 cell with CRISPR-mediated editing of RASGRPI ( $\operatorname{sg} R A S G R P I)$ (bottom) conjugated to K562 cells, detected with anti-a-tubulin (blue), anti-perforin (green) and phalloidin-stained F-actin (red). TL, transmitted light. (d-f) Actin density at the synapse (d), distance from lytic granule to MTOC (e), and granule convergence to MTOC (f) of RASGRP1 wild-type NK-92 control cells and sgRASGRP1 NK-92 cells. (g) Tandem affinity purification of RASGRP1 in Jurkat cells (left) and HEK cells (right), presented as FC-A scores versus FC-B scores. (h) Conservation of the KATQT motif in RASGRP1 and RASGRP3 across various vertebrate species. (i) HA-based co-immunoprecipitation of StrepHA-tagged wild-type (WT) RASGRP1, KATQT-mutant (mut) RASGRP1 or Strep-HAtagged-GFP with endogenous DYNLL1. ( $\mathbf{j}, \mathbf{k})$ Video microscopy of granule convergence in $\operatorname{sg} R A G S R P 1$ and control NK cells. $* P<0.05$ and $* * P<0.0001$ (unpaired Student's $t$ test). 
Data are representative of four $(\mathbf{c})$, three $(\mathbf{a}, \mathbf{c}-\mathbf{f}, \mathbf{i})$, two $(\mathbf{g}, \mathbf{j}, \mathbf{k})$ or one $(\mathbf{b})$ independent experiment(s) (mean and s.d. in $\mathbf{d}-\mathbf{f}, \mathbf{j}, \mathbf{k})$. 
a

g
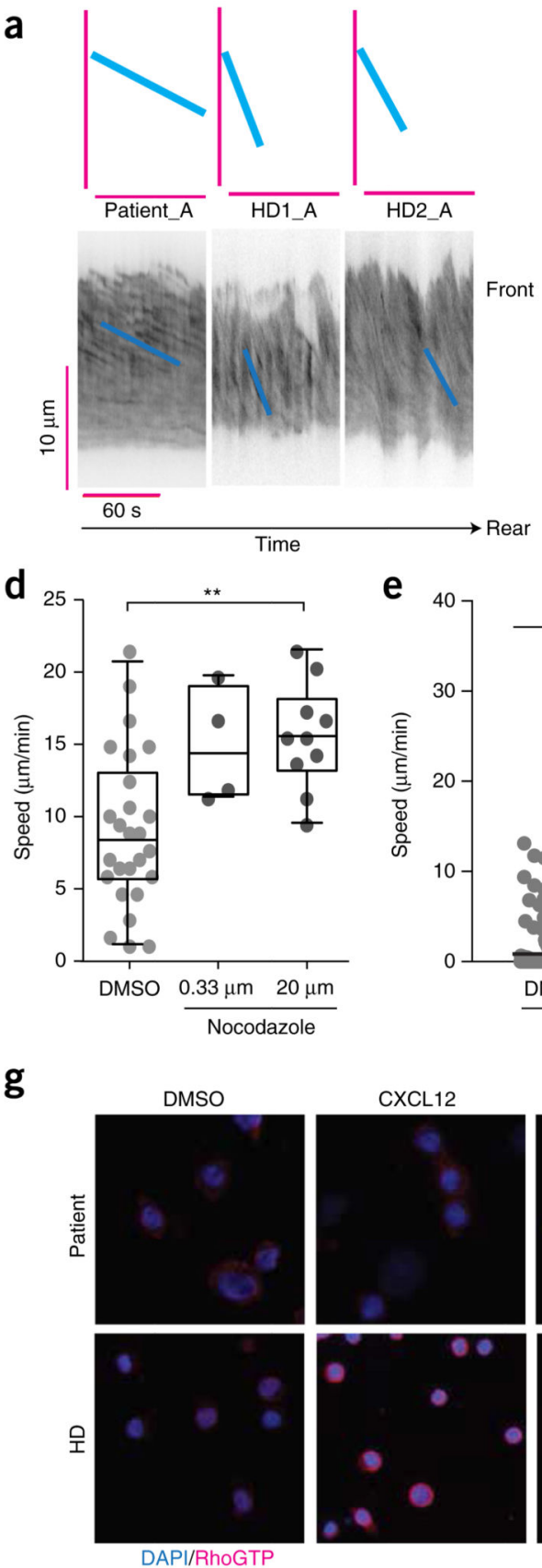

b

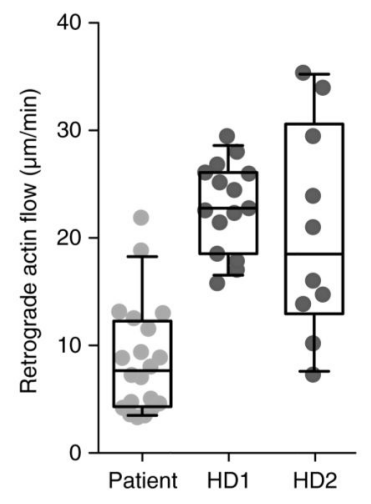

C

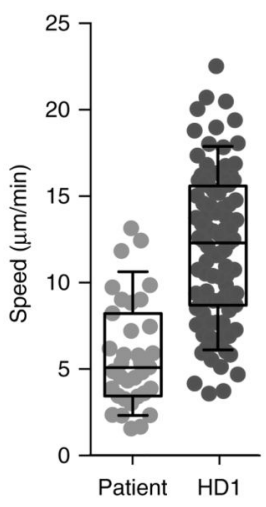

f

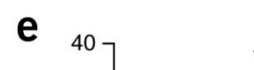

**
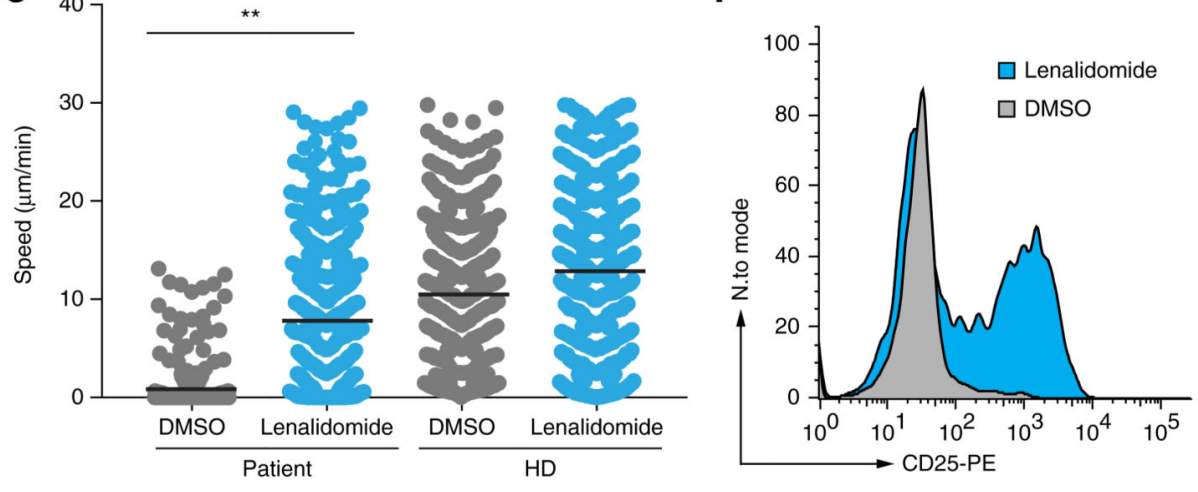

h

Lenalidomide
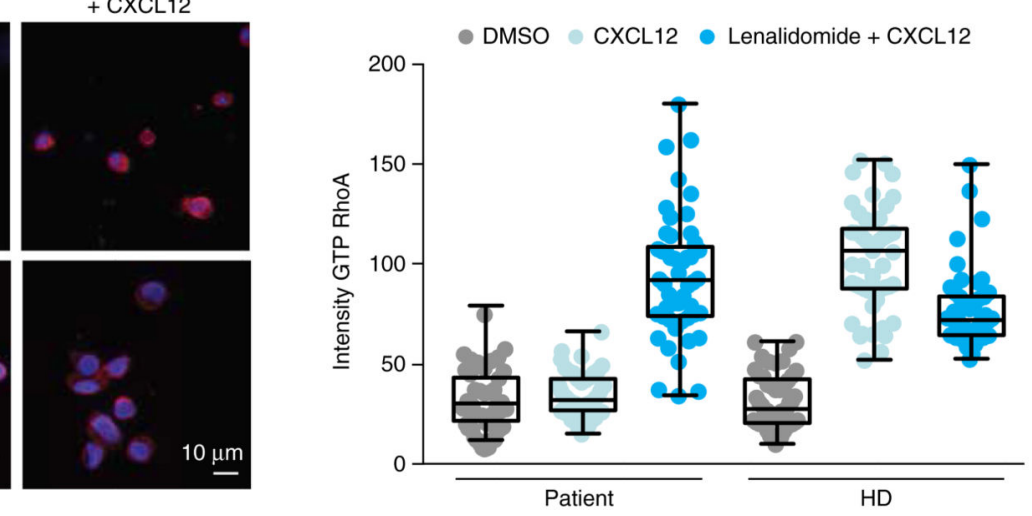

Figure 5. RASGRP1 deficiency leads to cell-migration defects that are reversed following treatment with lenalidomide.

(a) Kymographs of retrograde actin flow in $\mathrm{CD}^{+} \mathrm{T}$ cells from the patient and healthy donors after transfection with Lifeact. Each kymograph represents one cell. (b)

Quantification of retrograde actin flow in $\mathrm{CD}^{+} \mathrm{T}$ cells from the patient and two healthy donors. Each symbol represents one cell. (c) Migration speed of $\mathrm{CD}^{+} \mathrm{T}$ cells from the patient and healthy donors. (d) Migration speed of $\mathrm{CD} 8^{+} \mathrm{T}$ cells from the patient and healthy donors following the addition of nocodazole. (e) Migration speed of PBMCs from 
the patient and healthy donors after the addition of lenalidomide. (f) Flow cytometry analyzing the expression of $\mathrm{CD} 25$ on proliferating $\mathrm{T}$ cells obtained from the patient and incubated with lenalidomide (blue) or DMSO (gray). (g) Immunofluorescence microscopy of $\mathrm{CD} 8^{+} \mathrm{T}$ cells from the patient and a healthy control that underwent population expansion and were pre-treated for $16 \mathrm{~h}$ with either lenalidomide or DMSO and were activated for 5 min with CXCL12, then were stained for active RhoA-GTP (red) and counterstained with the DNA-binding dye DAPI (blue). (h) Quantification of immunofluorescence images as in g (50 cells per condition) by measurement of the mean intensity of total RhoA and RhoAGTP. $(P>0.05), * P \leq 0.05(\mathbf{e}), * * P<0.01(\mathbf{e})$ and $* * * P \leq 0.0001$ (ANOVA $(\mathbf{e}, \mathbf{d}))$ Data are representative of four $(\mathbf{c})$, or two $(\mathbf{a}, \mathbf{b}, \mathbf{e}, \mathbf{f}, \mathbf{g})$ independent experiments. 